Reviews 


\title{
Proteolytic Enzyme Therapy in Complementary Oncology: A Systematic Review
}

\author{
LENNART GREMMLER ${ }^{1}$, SABINE KUTSCHAN ${ }^{1}$, JENNIFER DÖRFLER ${ }^{1}$, \\ JUDITH BÜNTZEL ${ }^{2}$, JENS BÜNTZEL ${ }^{3}$ and JUTTA HÜBNER ${ }^{1}$ \\ ${ }^{1}$ Department for Hematology and Internal Oncology, Jena University Hospital, Jena, Germany; \\ ${ }^{2}$ Department for Hematology and Medical Oncology, University Medical Center Göttingen, Göttingen, Germany; \\ ${ }^{3}$ Department of Otorhinolaryngology, Südharz Clinic Nordhausen, Nordhausen, Germany
}

\begin{abstract}
Background/Aim: Bromelain, papain and chymotrypsin are proteolytic enzymes. They can be found in fruits such as pineapple or papaya, but also in the human body, namely in the pancreas. Besides their enzymatic function, they are said to reduce side-effects and even to improve the outcome of cancer therapies. We, therefore, aimed to critically examine and systematically review existing evidence on the role that these enzymes might play in cancer treatment. Materials and Methods: In May 2019, a systematic literature search was conducted by using five electronic databases (Embase, Cochrane, PsychInfo, CINAHL and Medline) to find studies concerning the use, effectiveness and potential harm of enzyme therapy on cancer patients. Results: Out of 13,046 search results, 15 studies with 3,008 patients were included in this systematic review. Patients treated with enzymes were diagnosed with various entities of gastrointestinal, gynecologic, head and neck and lung cancer as well as hematological malignancies. The therapy concepts included mainly oral intake of enzymes in addition to conventional therapies. Investigated outcomes were side-effects of anticancer therapy, quality of life, as well as anticancer effects and survival rates. In summary, due to conflicting results and moderate quality of the included studies, the evidence is insufficient to attribute positive effects to
\end{abstract}

This article is freely accessible online.

Correspondence to: Lennart Gremmler, Department for Hematology and Internal Oncology, Jena University Hospital, Am Klinikum 1, DE-07747 Jena, Germany. Tel: +49 36419324256, Fax: +49 36419324217, e-mail: lgremmler@yahoo.com

Key Words: Proteolytic enzymes, complementary medicine, nutritional supplements, immune system, bromelain, papain, chymotrypsin, review. enzymes in terms of better tolerability of the various antineoplastic therapies or even improvement in treatment efficacy. In most cases, enzyme therapy was well tolerated; sideeffects were mainly gastrointestinal complaints such as diarrhea or meteorism. Conclusion: On the basis of existing evidence, there is no clear therapeutic benefit of enzymes neither as supportive therapy nor as part of antineoplastic therapy.

Complementary and Alternative Medicine (CAM) is widely used by cancer patients today. Patients wish to actively act against this life-changing disease (1). In a survey of breast cancer patients, $77 \%$ of the surveyed were currently using CAM, mainly with the intention of reducing side-effects, boosting the immune system and becoming more active (2).

Enzyme therapy (more precisely the application of proteases like bromelain, papain or chymotrypsin that are of plant or animal origin) is a method of CAM, which is mainly used to mitigate side-effects of cancer treatment. Furthermore, enzyme therapy is supposed to influence the course of disease. The mechanism of action has not yet been conclusively clarified, but there are a number of possible explanations. Studies indicated that the serine proteases trypsin and chymotrypsin increase serum levels of the antiproteinases $\alpha 2$ macroglobulin and $\alpha 1$-antitrypsin (3). Research showed that antiproteinases have an impact on tumor cell metastasis, as seen in pancreatic cell carcinomas (4).

A similar mode of action is suspected for the cysteine proteinases bromelain and papain. Research recently indicated that the balance between cysteine proteinases and antiproteinases has an influence on metastases. Their use as a prognostic marker has also been discussed (5). Overall, proteolytic enzymes are considered to have an antiinflammatory effect, as demonstrated by Swamy and colleagues for trypsin, chymotrypsin and serratiopeptidase. They induced granuloma by cotton pellets on the rat model 
and observed the effects on the edema formed around (6). In addition, enzymes also play a role for wound debridement in order to remove slough, decrease exudate and preparing the wound base for grafting (7). While these studies may all implicate a potential beneficial effect of enzymes for treating cancer patients, there is no recent systematic appraisal in current literature. Therefore, we conducted a systematic review assessing data from clinical studies on the influence of enzymes on cancer therapy-related side-effects, quality of life, as well as effects on survival, cancer recurrence and metastasis to evaluate the existing clinical evidence.

\section{Materials and Methods}

Inclusion criteria. Inclusion and exclusion criteria are listed in Table I based on a PICO-model. All cancer entities were included. Criteria to reject studies were primary prevention, grey literature, other publication types than primary investigation/report (e.g., comments, letters, abstracts) and study populations with $>20 \%$ children (defined as subjects younger $<18$ years) or precancerous conditions, if results of adult patients with cancer were not reported separately. Additionally, studies were excluded in case they reported no patient centered outcomes.

Study design. We included systematic reviews and randomized controlled trials as well as cohort studies. One-armed studies were included only with respect to side-effects of enzyme therapy.

Study selection. A systematic research was conducted using five databases (Medline (Ovid), CINAHL (EBSCO), EMBASE (Ovid), Cochrane CENTRAL and PsycINFO (EBSCO)) in May 2019. For each of these databases a complex search strategy was developed consisting of a combination of Mesh Terms, keywords and text words in different spellings connected to cancer and enzyme therapy (Table II). A two-step search was executed starting with 1) a search string with restrictions for study or publication type to find systematic reviews and randomized controlled trials followed by 2) a search string without restrictions (minus the studies from the first search) to find studies of a lower evidence level. After importing the search results into EndNote X8, all duplicates were removed, and title-abstract-screening was carried out by two independent reviewers (LG and $\mathrm{JH}$ ). When title and abstract did not have sufficient information for screening purposes, a full-text copy was retrieved. Additionally, bibliography lists of all retrieved articles were searched for relevant studies. Language settings covered German and English articles.

Assessment of risk of bias and methodological quality: All characteristics were assessed by two independent reviewers (LG and SK). In case of disagreement a third reviewer was consulted (JH) and consensus was made by discussion. The risk of bias in the included studies was analyzed with the SIGN- Checklist (8) for controlled trials and cohort studies using the checklist's version 2.0 respectively 3.0. Additionally, we examined blinding of researchers, blinding of outcome assessment and comparability of groups before treatment, not only in terms of demographic variables, but also concerning the outcomes. The included studies were rated according to the Oxford criteria (Table III) (9). Additional criteria concerning methodology were size of population, application of power analysis, dealing with missing data and drop-out (report of drop-out reasons, application of intention-to-treat-analysis), adequacy of statistical tests (e.g., control of premises or multiple testing) and selective outcome reporting (report of all assessed outcomes with specification of statistical data as the p-value).

Outcomes. Clinical outcomes of interest included patient-centered outcomes which were the avoidance and alleviation of typical sideeffects or the tolerability of modern cancer therapy like surgery, chemotherapy, radiation or endocrine therapy. Endpoints investigated were mucositis, swallowing disorders, radiodermatitis, consumption of supportive medication, pain, swelling, edema, quality of life, gastrointestinal complaints and urogenital sideeffects. Next, we considered were therapy discontinuations, tolerability of cancer treatment, response to treatment, disease specific survival, remission and cancer recurrence or metastases. Finally, we assessed side-effects of the enzyme treatment itself.

Data extraction. Data extraction was performed by one reviewer (LG) and controlled by two independent reviewers (SK/JD, JH). Evidence tables from the national Guideline on Complementary and Alternative Medicine in Oncological Patients of the German Guideline Program in Oncology were used as a template for data extraction (10).

Participants. Included patients were characterized by type and stage of cancer, type of treatment (e.g., chemo-, hormone-, radiotherapy, operation), age and sex.

Intervention. Generally, all types of clinical studies were included if they reported patient-relevant outcomes following any intervention using enzyme therapy for treatment of adult cancer patients.

Comparison. Any kind of comparison was eligible in this review. This includes watch and wait, standard care and placebo strategies.

\section{Results}

The systematic research at all levels of evidence revealed 13,046 results. Four studies were added by hand search. At first, duplicates were removed leaving 9,156 studies. After screening for title and abstract, 93 studies remained and underwent further investigation. Finally, 15 publications were analyzed in this review, including 10 randomized controlled trials (RCT), 3 cohort studies and 2 single arm studies. The selection process of studies is presented by flow-diagrams in Figures 1 and 2. Detailed characterization of the included studies may be found in Table IV. Excluded studies are listed in Table V.

Patient characteristics in included studies. The studies included 3,008 patients. Due to at least 20 drop-outs a final number of 2,988 patients were analyzed. Since the majority of studies lacked data on drop out and attrition, the actual number of patients may be lower. The age of patients ranged from a mean of $23.76 \pm 5.48$ to $67.2 \pm 11.1$ years. A total of 1,840 participants were females and 1,100 males. 
Table I. Inclusion and exclusion criteria for studies using the PICO scheme.

\begin{tabular}{|c|c|c|}
\hline PICO & Inclusion criteria & Exclusion criteria \\
\hline Patient & $\begin{array}{l}\text { - Cancer patients (all entities and stages) } \\
\text { - Adult patients (age }>18 \text { ) }\end{array}$ & $\begin{array}{l}\text { - Patients with only precancerous conditions } \\
\text { or Carcinoma in situ } \\
\text { - Preclinical studies } \\
\text { - Study population with more than } 20 \% \text { children or } \\
\text { precancerous conditions }\end{array}$ \\
\hline Intervention & - Every intervention with enzymes (oral, rectal and intrapleural) & \\
\hline Comparison & - All possible control groups (placebo, standard care, observation) & - Other study types (case report or series) \\
\hline Outcome & $\begin{array}{l}\text { - Primary endpoints were all patient-relevant symptoms/toxicities, } \\
\text { secondary endpoints were response data, survival data, } \\
\text { and quality of life }\end{array}$ & $\begin{array}{l}\text { - No patient-centred data, for example } \\
\text { laboratory parameters }\end{array}$ \\
\hline Others & $\begin{array}{l}\text { - Meta-analyses, systematic reviews and RCTs, } \\
\text { cohort studies, one-armed studies } \\
\text { - Language: German and English } \\
\text { - Full publication }\end{array}$ & $\begin{array}{l}\text { - Grey literature (conference articles, abstracts, } \\
\text { letters, ongoing studies, unpublished literature) }\end{array}$ \\
\hline
\end{tabular}

Excluded studies. We excluded 2 single-arm studies with interventions using other drugs next to proteolytic enzymes as the effects of it was not possible to assess whether the reported effects were caused by the enzyme therapy or by another component of the intervention. Excluded studies are listed in Table V.

Mucositis and swallowing disorders due to radiotherapy. We assessed 3 randomized controlled trials (RCTs) examining the effect of the enzyme therapy on oral mucositis and swallowing disorders due to radiotherapy. In Dörr et al. (11) (where $\mathrm{N}=69$, tumors of the oral cavity), radiotherapy protocols comprised conventional fractionation with 1.8-2.0 Gy/fraction, $5 \times /$ week to total doses of $60-66$ Gy/6-7 weeks, or hyperfractionation with $2 \times 1.2 \mathrm{~Gy} /$ day, $5 \times /$ week to a total dose of 72 Gy/6-7 weeks; hyperfractionation was applied in $8 / 36(22 \%)$ patients in the intervention group and in $11 / 33$ $(33 \%)$ patients in the placebo group. The authors of the study found no significant differences between the interventionand the control group for maximum mucositis (summarized as the mean value of the maximum values collected; $p=0.317)$. However, there was a significant difference in the mean grade of mucositis in favor of the control group $(p=0.041)$ due to an earlier onset of mucositis in the intervention group. They observed no relevant group difference related to swallowing difficulties (11). Gujral et al. (control group patients received 58.6 \pm 8.8 Gy over $45 \pm 9$ days and intervention group patients received an average dose of $59.1 \pm 6.2$ Gy over $45 \pm 9$ days) examined 100 patients with head and neck tumors. They reported a significant difference in the maximum severity $(p<0.0001)$ and the mean severity of mucositis $(p=0.0001)$ in favor of the intervention group. They also described a significant difference for the time of occurrence in favor of the intervention group $(6.9 \pm 0.8$ vs. $5.7 \pm 1.2$ weeks; $p=0.0014)$. In addition, they found a significant difference in the maximum severity $(1.32 \pm 0.64 v s .2 .24 \pm 0.60 ; p<0.0001)$, the mean value - evaluated as area under the curve $(5.2 \pm 3.4 \mathrm{vs}$. $10.1 \pm 3.6 ; p=0.0001 ;$ ) and the duration until swallowing problems (Grade I: $5.2 \pm 1.5$ vs. 3.6 \pm 0.5 ; Grade II 7.3 \pm 0.8 vs. $6.1 \pm 1.3$ weeks; $p=0.0092 ; p=0.0064)$ in favor of the intervention group. The classification was based on the RTOG/EORTC criteria (12). Vinzenz et al. ( $\mathrm{N}=39$, carcinoma of the oral cavity; irradiation with the gammatron was performed for a period of 5 weeks spread over several sessions in both groups, total cumulative dose $50 \mathrm{~Gy}$ ) found a significant difference in severity of mucositis in favor of the intervention group (stage I: $21.4 \%$ vs. $0 \%$, II: $68.4 \%$ vs. $55 \%$, III: $10.5 \%$ vs. $45 \% ; p=0.014)$. There were also significantly more patients with mucositis stage III in the control group $(p=0.019)$. First appearance of mucositis was earlier in the intervention group with $9.1( \pm 4.9)$ days $v s .13$ ( \pm 4.1 ) days (median $9.0 \mathrm{vs} .12 .5$; $p=$ not stated) (13).

In summary, 2 of 3 studies described a benefit of enzyme therapy. In contrast, the study with the highest quality, which is the only blinded one, described an advantage of the control group. In the presence of inconclusive studies, no recommendation for or against enzyme therapy can be made.

Radiodermatitis and additionally required supportive or analgesics drugs due to cancer treatment. We assessed 4 RCTs and 1 cohort study examining the effect of enzyme 
Table II. Search strategy consisting of a combination of mesh terms, keywords and text words in various spellings related to cancer and enzyme therapy.

Database Search string

Ovid Medline

1 Bromelains/ or Papain/ or Chymotrypsin/ or Trypsin/ or (bromel?in? or papain? or chymotrypsin? or trypsin? or an?anase or traumanase or papase or (papaya adj1 (peptidase or proteinase)) or papayotin or (pepsin adj1 vegetable) or vemizym or innovazym or phlogenzym or proteozym or rutozym or traumazym or wobenzym or dogenzyme or (wobe adj1 mu?os) or (proteolytic adj1 enzyme?)).mp.

2 exp neoplasms/ or neoplasm\$.mp or cancer\$.mp. or tumo?r\$.mp. or malignan\$.mp. or oncolog\$.mp. or carcinom\$.mp. or leuk?emia.mp. or lymphom\$.mp. or sarcom\$.mp.

31 AND 2

4 limit 3 to English or limit 3 to German

5 limit 4 to $\mathrm{yr}=" 1995$-Current"

6 (5 and humans/) or (5 not animals/)

7 (((comprehensive* or integrative or systematic*) adj3 (bibliographic* or review* or literature)) or (meta-analy* or metaanaly* or "research synthesis" or ((information or data) adj3 synthesis) or (data adj2 extract*))).ti,ab. or (cinahl or (cochrane adj3 trial*) or embase or medline or psyclit or (psycinfo not "psycinfo database") or pubmed or scopus or "sociological abstracts" or "web of science" or central).ab. or ("cochrane database of systematic reviews" or evidence report technology assessment or evidence report technology assessment summary).jn. or Evidence Report: Technology Assessment*.jn. or network adj1 analy*.ti,ab.) or (((review adj5 (rationale or evidence)).ti,ab. and review.pt.) or meta-analysis as topic/ or Meta-Analysis.pt.)

8 Randomi?ed controlled trial?.pt. or controlled clinical trial?.pt. or randomi?ed.ti,ab.or placebo.ti,ab. or drug therapy.sh. or randomly.ti,ab. or trial?.ti,ab. or group?.ti,ab.

96 AND (7 OR 8)

106 NOT 9

Ovid Embase

1 Bromelains/ or Papain/ or Chymotrypsin/ or Trypsin/ or (bromel?in? or papain? or chymotrypsin? or trypsin? or an?anase or traumanase or papase or (papaya adj1 (peptidase or proteinase)) or papayotin or (pepsin adj1 vegetable) or vemizym or innovazym or phlogenzym or proteozym or rutozym or traumazym or wobenzym or dogenzyme or (wobe adj1 mu?os) or (proteolytic adj1 enzyme?)).mp.

2 exp neoplasms/ or neoplasm\$.mp or cancer\$.mp. or tumo?r\$.mp. or malignan\$.mp. or oncolog\$.mp. or carcinom\$.mp. or leuk?emia.mp. or lymphom\$.mp. or sarcom\$.mp.

31 AND 2

4 limit 3 to English or limit 3 to German

5 limit 4 to $y r=" 1995$-Current"

6 (5 and humans/) or (5 not animals/)

7 ((( (comprehensive* or integrative or systematic*) adj3 (bibliographic* or review* or literature)) or (meta-analy* or metaanaly* or "research synthesis" or ((information or data) adj3 synthesis) or (data adj2 extract*))).ti,ab. or (cinahl or (cochrane adj3 trial*) or embase or medline or psyclit or (psycinfo not "psycinfo database") or pubmed or scopus or "sociological abstracts" or "web of science" or central).ab. or ("cochrane database of systematic reviews" or evidence report technology assessment or evidence report technology assessment summary).jn. or Evidence Report: Technology Assessment*.jn. or (network adj1 analy*).ti,ab.) or (exp Meta Analysis/ or ((data extraction.ab. or selection criteria.ab.) and review.pt.))

8 crossover procedure/ or double blind procedure/ or randomized controlled trial/ or single blind procedure/ or (random\$ or factorial\$ or crossover\$ or (cross adj1 over\$) or placebo \$ or (doubl\$ adj1 blind\$) or (singl\$ adj1 blind\$) or assign \$ or allocat\$ or volunteer\$).ti,ab,de.

96 AND (7 OR 8)

106 NOT 9

Cochrane

\#1 [mh Bromelains] or [mh Papain] or [mh Chymotrypsin] or [mh Trypsin] or bromel?in? or papain? or chymotrypsin? or trypsin? or an?anase or traumanase or papase or (papaya NEXT (peptidase or proteinase)) or papayotin or (pepsin NEXT vegetable) or vemizym or innovazym or phlogenzym or proteozym or rutozym or traumazym or wobenzym or dogenzyme or (wobe NEXT mu?os) or (proteolytic NEXT enzyme?)

\#2 [mh neoplasms] or neoplasm* or cancer? or tum*r? or malignan* or oncolog* or carcinom* or leuk*mia or lymphoma? or sarcoma?

\#3 1 AND 2

Ebsco - PsychINFO S1 TX (bromel\#in\# or papain\# or chymotrypsin\# or trypsin\# or an\#anase or traumanase or papase or (papaya N1 (peptidase or proteinase)) or papayotin or (pepsin N1 vegetable) or vemizym or innovazym or phlogenzym or proteozym or rutozym or traumazym or wobenzym or dogenzyme or (wobe N1 mu\#os) or (proteolytic N1 enzyme\#)) 
Table II. Continued

\begin{tabular}{ll}
\hline Database & Search string \\
\hline S2 ((DE "Neoplasms" OR DE "Benign Neoplasms" OR DE "Breast Neoplasms" OR DE "Endocrine Neoplasms" OR DE \\
"Leukemias" OR DE "Melanoma" OR DE "Metastasis" OR DE "Nervous System Neoplasms" OR DE "Terminal Cancer") \\
OR (TX neoplasm* OR TX cancer OR TX tumo\#r OR TX malignan* OR DE „oncology“ OR TX oncolog* OR TX \\
carcinom* OR TX leuk\#emia OR TX lymphoma OR TX sarcoma)) \\
S3 (LA German OR LA English) \\
S4 S1 AND S2 AND S3 \\
S5 ((comprehensive* OR integrative OR systematic*) N3 (bibliographic* OR review* OR literature)) OR (meta-analy* or \\
metaanaly* or "research synthesis" OR ((information OR data) N3 synthesis) OR (data N2 extract*)) OR ((review N5 \\
(rationale OR evidence)) AND DE "Literature Review") OR (AB(cinahl OR (cochrane N3 trial*) OR embase OR medline \\
OR psyclit OR pubmed OR scopus OR "sociological abstracts" OR "web of science" OR central)) OR DE "Meta Analysis" \\
OR (network N1 analy*) \\
S6 DE "Treatment Effectiveness Evaluation" OR DE "Treatment Outcomes" OR DE "Psychotherapeutic Outcomes" OR DE \\
"Placebo" OR DE "Followup Studies" OR placebo* OR random* OR "comparative stud*" OR (clinical N3 trial*) OR \\
(research N3 design) OR (evaluat* N3 stud*) OR (prospectiv* N3 stud*) OR ((sing1* OR doubl* OR treb1* OR tripl*) N3 \\
(blind* OR mask*) \\
S7 S4 AND (S5 OR S6) \\
S8 S4 NOT S7
\end{tabular}

Ebsco- CINAHL S1 MH Trypsin or MH Chymotrypsin or TX (bromel\#in\# or papain\# or chymotrypsin\# or trypsin\# or an\#anase or traumanase or papase or (papaya N1 (peptidase or proteinase)) or papayotin or (pepsin N1 vegetable) or vemizym or innovazym or phlogenzym or proteozym or rutozym or traumazym or wobenzym or dogenzyme or (wobe N1 mu\#os) or (proteolytic N1 enzyme\#))

S2 (MH "Neoplasms+" OR TX neoplasm* OR TX cancer OR TX tumo\#r OR TX malignan* OR TX oncolog* OR TX carcinom* OR TX leuk\#emia OR TX lymphoma OR TX sarcoma OR MH "Precancerous Conditions+" OR TX precancer* OR TX preneoplas*)

S3 (LA German OR LA English)

S4 S1 AND S2 AND S3

S5 (TI (systematic* n3 review*)) or (AB (systematic* $\mathrm{n} 3$ review*)) or (TI (systematic* $\mathrm{n} 3$ bibliographic*)) or $(\mathrm{AB}$ (systematic* $\mathrm{n} 3$ bibliographic*)) or (TI (systematic* $\mathrm{n} 3$ literature)) or (AB (systematic* $\mathrm{n} 3$ literature)) or (TI (comprehensive* $\mathrm{n} 3$ literature) ) or ( $\mathrm{AB}$ (comprehensive* $\mathrm{n} 3$ literature)) or (TI (comprehensive* $\mathrm{n} 3$ bibliographic*)) or (AB (comprehensive* $\mathrm{n} 3$ bibliographic*)) or (TI (integrative $\mathrm{n} 3$ review)) or (AB (integrative $\mathrm{n} 3$ review)) or (JN "Cochrane Database of Systematic Reviews") or (TI (information $\mathrm{n} 2$ synthesis)) or (TI (data $\mathrm{n} 2$ synthesis)) or (AB (information $\mathrm{n} 2$ synthesis)) or (AB (data $\mathrm{n} 2$

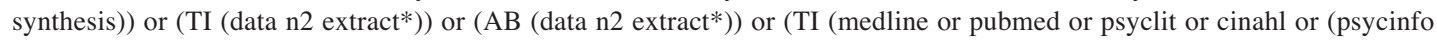
not "psycinfo database") or "web of science" or scopus or embase)) or (AB (medline or pubmed or psyclit or cinahl or (psycinfo not "psycinfo database") or "web of science" or scopus or embase or central)) or (MH "Systematic Review") or (MH "Meta Analysis") or (TI (meta-analy* or metaanaly*)) or (AB (meta-analy* or metaanaly*)) or TI (network analy*) or $\mathrm{AB}$ (network analy*)

S6 (MH "Clinical Trials+") or PT Clinical trial or TX clinic* n1 trial* or TX ((singl* n1 blind*) or (singl* n1 mask*)) or TX ((doubl* n1 blind*) or (doubl* n1 mask*)) or TX ((tripl* n1 blind*) or (tripl* n1 mask*)) or TX ((trebl* n1 blind*) or (trebl* $\mathrm{n} 1$ mask*)) or TX randomi* control* trial* or (MH "Random Assignment") or TX random* allocat* or TX placebo* or MH "Placebos") or MH "Quantitative Studies") or TX allocat* random*

S7 S4 AND (S5 OR S6)

S8 S4 NOT S7

therapy on radiodermatitis. Dale et al. included 120 patients with cervical cancer undergoing radiotherapy and evaluated the effects of enzyme therapy on radiodermatitis according to RTOG/EORTC grading. There was a significant difference between the mean maximum extent in favor of the enzyme group with $0.97 \pm 0.82 v s .1 .68 \pm 0.87(p<0.001)$. They found no group difference in the consumption of supportive medication (14). Gujral et al. addressed the maximum expression of the radiodermatitis in 100 patients with head and neck tumor as well as their average grade over time
(RTOG/EORTC). The maximum radiodermatitis in the intervention group was significantly lower compared to the control group $(1.23 \pm 0.75$ vs. $2.39 \pm 1.10, \quad p<0.0001)$, measured as a lower level of the area under the curve $(3.9 \pm 2.9 v s .9 .5 \pm 3.9 ; p=0.0001)$ and as later appearance (grade II, 6.6 \pm 1.6 vs. $5.7 \pm 1.4$ weeks; $p=0.0048$ ) (12). Beuth et al. assessed radiodermatitis in a cohort study with 649 patients with non-metastatic breast cancer. There was a significant mean difference in symptoms in in favor of the intervention group. Treatment success occurred in $38 \%$ of 
Table III. Risk tables of included studies using the Oxford criteria.

\begin{tabular}{ccccc}
\hline Reference & $\begin{array}{c}\text { Study } \\
\text { type }\end{array}$ & $\begin{array}{c}\text { Standardized } \\
\text { rating of risk } \\
\text { of bias }\end{array}$ & Additional comments on methodology & $\begin{array}{c}\text { Evidence } \\
\text { Level } \\
\text { (Oxford) }\end{array}$ \\
\hline
\end{tabular}

\begin{tabular}{lcc}
\hline $\begin{array}{l}\text { Dale } \text { et al. } \\
\text { (14) (2001) }\end{array}$ & RCT & SIGN \\
& Positive: 7 & PRO: Ethics vote; adjusted for multiple testing by the step-down method of \\
Uncertain: 0 & Bonferroni-Holm; Baseline criteria/group comparability is specified;
\end{tabular}

Negative: 1

Overall quality: Acceptable

Dörr et al. RCT SIGN

(11) (2007) Positive: 8

Uncertain: 1

Negative: 0

Overall quality:

Acceptable

Gujral et al. RCT SIGN

(12) (2001) Positive: 5

Uncertain: 3

Negative: 1

Overall quality:

Acceptable

Martin et al. RCT SIGN

(16) (2002) Positive: 5

Uncertain: 3

Negative: 0

Overall quality:

Acceptable

Stauder et al. RCT

(21) (1991)

SIGN

Positive: 4

Uncertain: 2

Negative: 2

Overall quality:

Acceptable

Tan et al.

RCT

SIGN

(17) (2018)
Positive: 4

Uncertain: 2

Negative: 2

Overall quality:

Acceptable
CONTRA: No blinding or placebo group; all evaluations made by one single person; number of Bonferroni-Holm corrections not comprehensible; unclear when attrition took place; disproportionately positive presentation of non-significant results

PRO: Triple-blinded; attrition specified in detail; patients scores were recorded by two investigators once a week and by another once more per week; intention-totreat analysis; power analysis; group comparability with the exception of gender

CONTRA: No baseline $p$-values given - the authors report only that they are comparable except for gender; relatively low number of study participants and relatively high attrition; no description of how the blinding was performed; no statistical values given for endpoints (mean, standard deviation, etc., only graphical representation with $p$-values); only graphical representation with $p$-value, without mean values, standard deviation; analyses partly not transparent

PRO: Ethics vote; group comparability is specified; adjusted for multiple testing by the step-down method of Bonferroni-Holm; patient compliance verified by pill count; follow-up carried out (despite high attrition)

CONTRA: No blinding or placebo group; in the reporting, the number of patients varies - sometimes without any explanation; all evaluations made by one single person

PRO: Double blinded; intention-to-treat analysis

CONTRA: Information on group comparability insufficient; possibly incorrect statistical instrument was used; relatively low number of study participants and high attrition; period but no reasons given for attrition; data collection by interview, possibly no objective survey; unclear randomization process; partially missing group comparisons

PRO: -

CONTRA: No information on the patients gender; according to the authors, the comparability of the groups was assessed by means of the Mann-Whitney- $U$-Test,

the Wilcoxon-Test to test significant differences between the symptom manifestations, the Mann-Whitney- $U$-Test to test significant differences between the therapy results and the ANOVA and LSD-Test to describe the course of symptoms - unfortunately, these results and corresponding $p$-values are not presented in the study; no blinding; no information on drop-out/attrition; the survey of side-effects was influenced by the fact that patients with known intolerance were excluded beforehand

PRO: Ethics vote; detailed specification of statistical parameters; group comparability is specified

CONTRA: Relatively low number of study participants; no information on drop-out or attrition: "If the participants suffered from side-effects, they stopped treatment and discontinued participation in the study"; the authors state that the study was conducted double-blinded, but this is not possible due to different treatment of the two arms; endpoint four is not independent of endpoints one, two and three; no correction for multiple testing

(cumulative $\alpha$-error possible); unclear randomization process 
Table III. Continued

\begin{tabular}{lcccc}
\hline Reference & $\begin{array}{c}\text { Study } \\
\text { type }\end{array}$ & $\begin{array}{c}\text { Standardized } \\
\text { rating of risk } \\
\text { of bias }\end{array}$ & Additional comments on methodology & $\begin{array}{c}\text { Evidence } \\
\text { Level } \\
(\text { Oxford })\end{array}$ \\
\hline Vinzenz et al. & RCT & SIGN & PRO: Information on the tests that were used & $2 \mathrm{~b}-$
\end{tabular}

Vinzenz et al. RCT SIGN

(13) (1992)

Uncertain: 5

Negative: 1

Overall quality:

Acceptable

$\begin{array}{lcc}\begin{array}{l}\text { Wrbka } \text { et al. } \\ \text { (19) (1978) }\end{array} & \text { RCT } & \text { SIGN } \\ & & \text { Positive: } 1 \\ & & \text { Uncertain: } 4 \\ & \text { Negative: } 3 \\ & & \text { Overall quality: } \\ & & \text { Acceptable } \\ \text { Kasseroller } & \text { RCT } & \text { SIGN } \\ \text { et al. }(18) & & \text { Positive: } 6 \\ \text { (2003) } & & \text { Uncertain: } 2 \\ & & \text { Negative: } 0 \\ & & \text { Overall quality: } \\ & & \text { Acceptable }\end{array}$

Beuth et al. cohort SIGN

(15) (2001) study Positive: 6

Uncertain: 1

Negative: 5

Overall quality:

Acceptable

Popiela et al. cohort SIGN

(20) (2001) study Positive: 7

Uncertain: 1

Negative: 4

Overall quality:

Acceptable
CONTRA: No ethics vote; hardly any demographic data and unclear randomization process, a comparability of the groups cannot be proven in a comprehensible way; relatively small number of study participants; no blinding; no information about drop-out or attrition; baseline $p$-values not given; no information whether monocentric or multicentric; no information on country and period of study

PRO: -

$2 b-$

CONTRA: Results almost not usable; no baseline values; graphs hardly readable; many different cancer entities despite small sample; unclear whether monocentric or multicentric; only 16 patients in the evaluation of therapy success (even if this was inevitably caused by deaths); no statistical group comparisons; no ethics vote

PRO: Detailed information on the baseline criteria; comparability of groups and general conditions was given, except for prior irradiation, hormone therapy and skin fold thickness of the affected hand;

Intention-to-treat analysis; double-blind; pill counting as control (compliance)

CONTRA: No ethics vote; no further information on drop-out/attrition; statistical methods presented in a way that is difficult to understand; no statistically verifiable substantiation of the results or group comparisons; one endpoint was the evaluation of success by the physician and the patient, but the result is not reported

PRO: Given comparability of the groups for the clinically relevant characteristics, even if this is not directly statistically stored; adequate application of statistical methods; sensitivity analysis with propensity score and thus control for missing randomization; other inequalities to the baseline (covariates: age, tumor stage, primary therapy response, duration of postoperative treatment, type of therapy, specialization and place of work of the physician)

CONTRA: Differences between the groups in the baseline criteria; no further information on drop-out/attrition; long time lag between the median follow-up in $\mathrm{A}$ and $\mathrm{B}$; no measures of dispersion given for age; no ethics vote

PRO: Large sample; detailed specification of the baseline criteria, Bonferroni correction was applied; sensitivity analysis with propensity score (covariates: enzyme treatment, tumor stage, postoperative response, Karnofsky index at baseline, duration of intervention/observation, age, sex, type of antineoplastic therapy, type of center); the multivariate Mann Whitney $U$ statistics were used for the evaluation; intention-to-treat for security analysis

CONTRA: Significant baseline differences in the mono subgroup (no other complementary medicine preparations were taken here except enzymes) in terms of tumor type, symptoms, remaining tumor mass, study centers; no statistical analysis is listed - only descriptive data ; the two sub-control groups differed from each other (the latter data are not listed and are not statistically proven); little information on the methods used to collect data on the endpoints, making it difficult to understand the process (no explanation of the endpoint "performance index"); mean time to follow-up was 275 days in A and 184 days in B; the primary endpoint "disease associated signs and symptoms" consists of 17 sub-points, but only a summary result is given; reasons for exclusion of study participants not specified; no ethics vote
$2 b$ 
Table III. Continued

\begin{tabular}{|c|c|c|c|c|}
\hline Reference & $\begin{array}{c}\text { Study } \\
\text { type }\end{array}$ & $\begin{array}{l}\text { Standardized } \\
\text { rating of risk } \\
\text { of bias }\end{array}$ & Additional comments on methodology & $\begin{array}{c}\text { Evidence } \\
\text { Level } \\
\text { (Oxford) }\end{array}$ \\
\hline $\begin{array}{l}\text { Sakalova } \\
\text { et al. } \\
\text { (22) (2001) }\end{array}$ & $\begin{array}{l}\text { cohort } \\
\text { study }\end{array}$ & $\begin{array}{c}\text { SIGN } \\
\text { Positive: } 8 \\
\text { Uncertain: } 0 \\
\text { Negative: } 4 \\
\text { Overall quality: } \\
\text { Acceptable }\end{array}$ & $\begin{array}{l}\text { PRO: Detailed information on the baseline criteria; results were partly evaluated } \\
\text { according to the intention-to-treat protocol; very detailed presentation of results, } \\
\text { adequate statistical approach; check for conflicting variables } \\
\text { CONTRA: No further information on drop-out/attrition; significant baseline differences } \\
\text { between the two groups in terms of "age for the total sample adjusted for disease stage" } \\
\text { (the authors regarded } 4 \text { years as not clinically relevant), laboratory parameters and } \\
\text { treatment regimes in stage III (poly-chemotherapy combinations); patients, who took the } \\
\text { enzyme for less than } 6 \text { months, were included in the control group; basic decision } \\
\text { whether enzymes were administered to patients depended on their current availability, } \\
\text { thus randomization cannot be assumed; number of people in intention-to-treat } \\
\text { varies from table to text; no ethics vote }\end{array}$ & $2 b$ \\
\hline
\end{tabular}

SIGN: Scottish Intercollegiate Guidelines Network Methodology: Checklist 2: Randomized Controlled Trials, Cohort Studies.

patients in the intervention- and $60 \%$ in the control group with respect to skin reactions, resulting in a significant difference in favor of the intervention group after adjustment with the propensity score $(p=0.006)(15)$.

Two studies did not find significant effects of enzyme therapy concerning skin complaints and additionally required supportive or analgesic drugs: One assessed dryness and moist skin detachment $(p=0.33, p=0.57)$ (11) and the other assessed epitheliolysis in context of grade $(p=0.16)$ or mean values ( $p=$ not stated) (16).

In summary, 3 out of 5 studies described an advantage of enzyme therapy. The other 2 studies did not show a significant result in favor of enzyme therapy. One study showed a non-significant trend in favor of the control group. In the presence of inconclusive studies, no recommendation can be made for or against enzyme therapy.

Pain, swelling, edema and associated quality of life. We assessed 3 RCTs examining the effect of enzyme therapy on pain, swelling, edema and the associated quality of life. Tan et al. assessed 72 patients with malignant hematological diseases, who had undergone prophylactic wisdom tooth extraction. Pain was assessed by visual analogue scale. At day 1, 3 and 7, there were significant differences in favor of the intervention group ( $p=0.013, p=0.019, p=0.044)$. This study also compared the limitation of mouth opening due to swelling. There was a significant difference in favor of the intervention group $(p<0.0001)$. Quality of life, assessed one week after tooth extraction by the modified postoperative symptom severity scale (PoSSE with 7 dimensions: food, language, feeling, swelling, pain, nausea, and daily living.), showed significant differences in favor of the intervention group in all categories (17). Swelling, documented by imaging, also was significant in favor of the intervention group $(p<0.0001)$ (17). Kasseroller et al. examined 88 patients with breast cancer with secondary lymphedema due to axillary lymphonodectomy. There was no significant difference in volume or skinfold thickness as a parameter for fibrosis between the two groups after 45 days in the upper arm. Similar results were reported for the lower arm, hand and third finger, with a slight advantage for the intervention in the lower arm and hand, without further statistical evaluation. A significant advantage for the intervention group was found in skin tension as assessed by the investigator on a rating scale from 0 to 3 (baseline: 2.0; day 45: $0.4 \mathrm{vs}$. 1.8; day 45: 0.5;) (18). Wrbka et al. evaluated the success of therapy from 51 patients with bronchopulmonary carcinoma based on a constant or improved X-ray image. With regard to quality of life, a benefit was shown the intervention group. No statistical data was provided for this result (19).

Overall, the study situation for postoperative edema and lymphedema is poor, with only one study each. Nevertheless, it can be said that enzymes seem to have a benefit for postoperative edema, whereas this is not the case for lymphedema. In terms of quality of life, the assessment is positive in both studies. A final recommendation for or against enzyme therapy cannot be given due to the limited number of studies and qualitative limitations of the studies.

Gastrointestinal complaints and urogenital side-effects due to cancer treatment. We assessed 2 RCTs and 1 cohort study examining the endpoint gastrointestinal complaints and 1 of them regarding urogenital side-effects and side-effects or damage on the vaginal mucosa as well. Martin et al. and Dale et al. evaluated different toxicity parameters from 56 and 120 patients during radiotherapy treatment by 


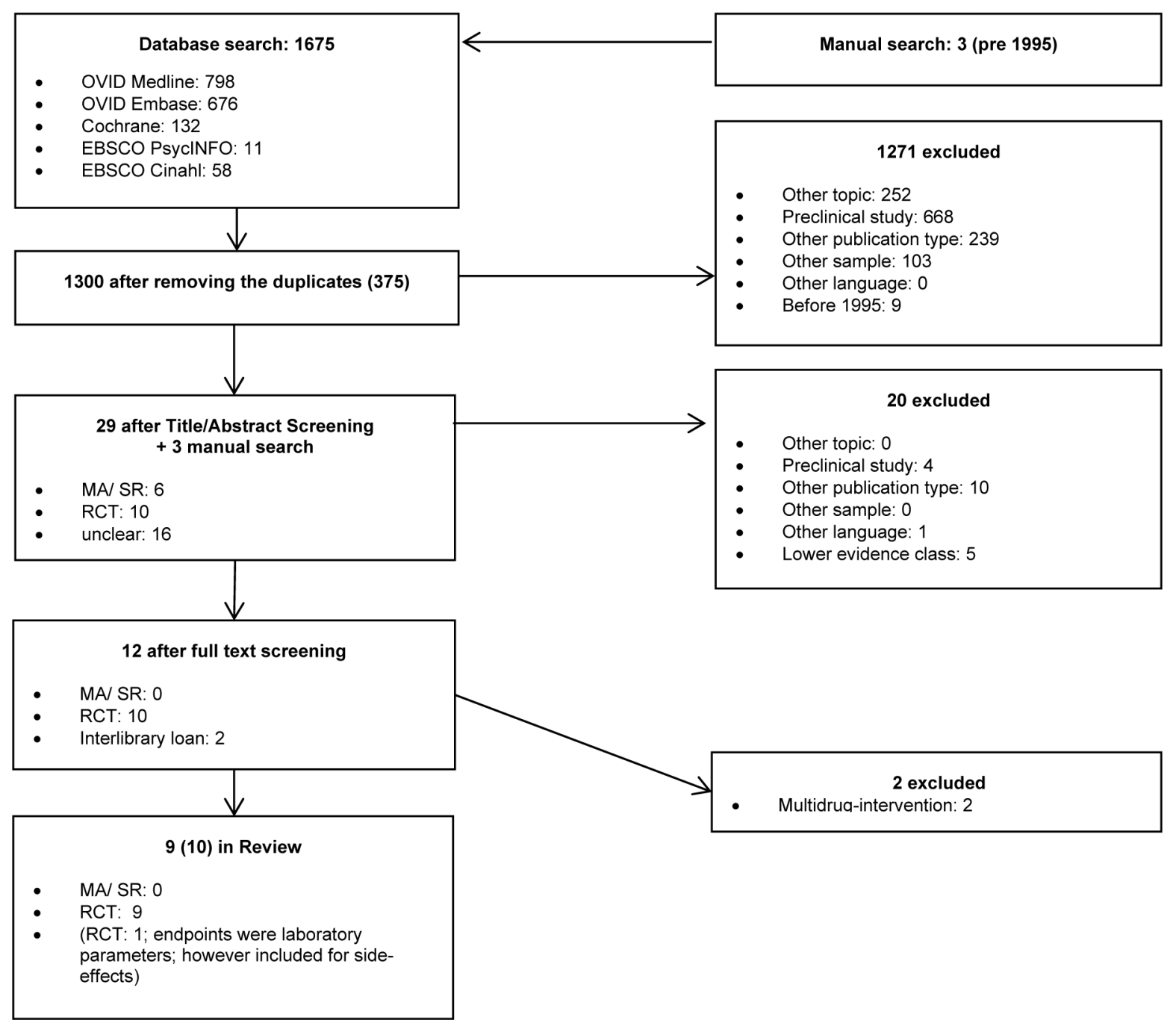

Figure 1. Flowchart - RCT.

RTOG/EORTC grading. No significant difference for severity of diarrhea $(p=0.11)$ and other gastrointestinal sideeffects $(p=0.12)$ was found between the intervention- and the control group $(14,16)$.

Beuth et al. described a significant difference in favor of the intervention group for gastrointestinal symptoms of their breast cancer patients under antineoplastic therapy (primary surgical treatment, radiation, adjuvant systemic endocrine or/and chemotherapy, $\mathrm{N}=649,0.27$ vs. $0.11 ; p=0.005)$. Treatment success, defined as a total suspension of symptoms (nausea, vomiting, changes in appetite, stomach pain or stomach disorder), was also in favor of the intervention $(p=0.042)(15)$. Dale et al. (patients in both arms received $50 \pm 60$ Gy of external beam radiation in $25 \pm 30$ fractions over a period of 5 weeks, followed by intra-cavitary brachytherapy at a dose of $20 \pm 30$ Gy using a BARC applicator) assessed acute urogenital side-effects according to the RTOG/EORTC grading of their 120 cervical cancer patients under radiation therapy, with a significant difference in favor of the intervention group $(0.93 \pm 0.52$ vs. $1.38 \pm 0.56$; $p<0.001)$ (14). No significant differences were found for side-effects or damage to the vaginal mucosa $(p=0.10)(14)$.

Considering the limited evidence of these studies, enzyme therapy might have benefit for urogenital adverse events, whereas the study evidence for gastrointestinal conditions is conflicting. No benefit was found for vaginal mucosa.

Therapy discontinuations and other side-effects due to antineoplastic therapy. Four RCTs and 2 cohort studies assessed further side-effects and therapy continuations due to antineoplastic therapy. Beuth et al. evaluated mean values and treatment success of specific symptoms from 649 patients by 


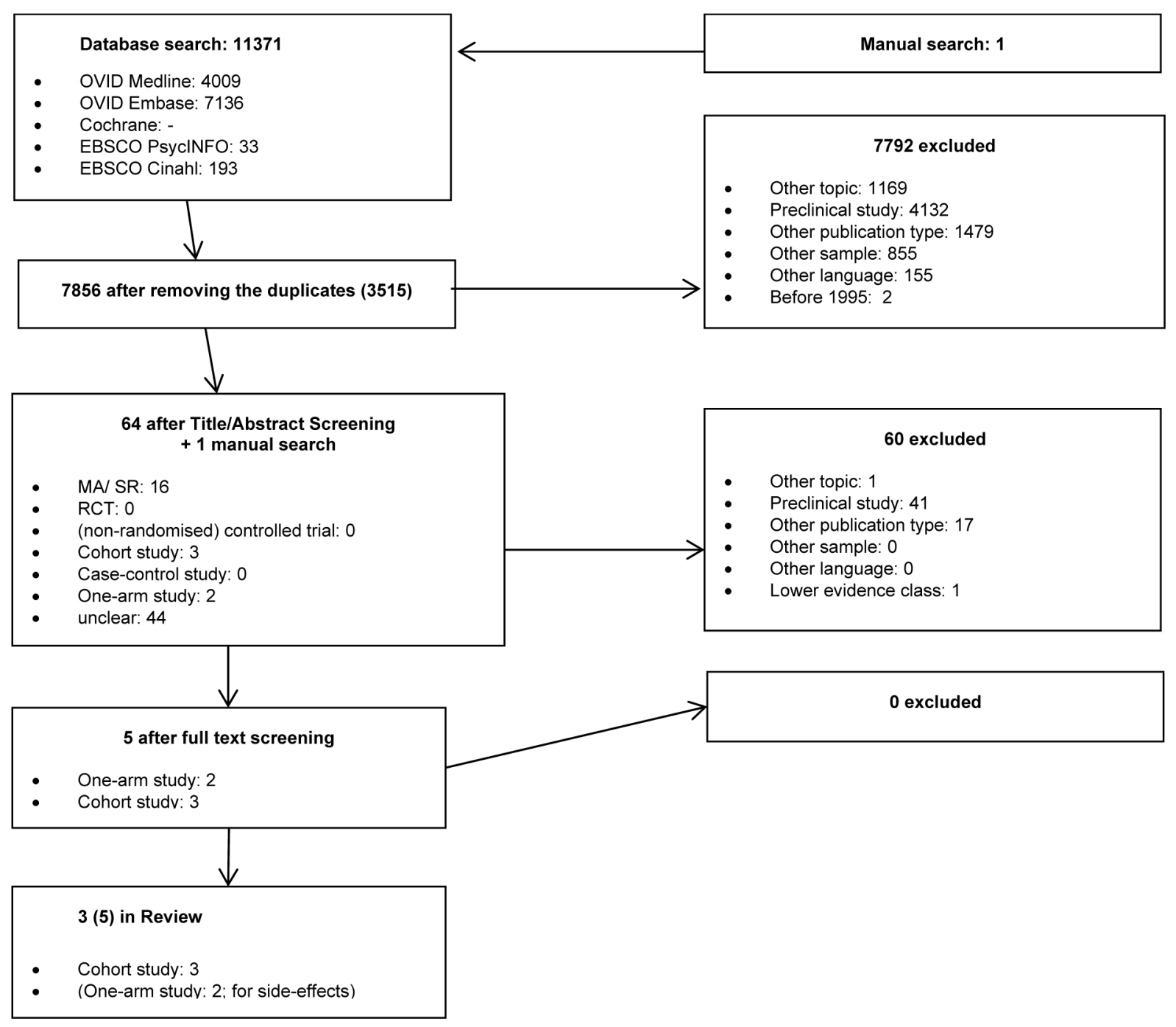

Figure 2. Flowchart - lower evidence class.

comparing them with previously collected basic values. A significant reduction in symptoms compared to the control group was detected for mental side-effects, dyspnea, headache and cachexia (all $p<0.05$ ). No significant differences were found for tumor pain and infections. A complete cessation of symptoms in favor of the intervention group arose for cachexia (65\% vs. $7 \% ; p=0.008)$ but not for mental side-effects, dyspnea, headache, tumor pain and infections (15). Popiela et al. (patients with colorectal cancers under antineoplastic therapy; primary surgical treatment, adjuvant systemic chemotherapy, radiotherapy) evaluated the number of adverse reactions of 1,242 patients. There was a slight superiority of the intervention-group between the groups $(0.6339 ; p<0.0001)(20)$.

Two studies did not find any group differences in terms of toxicity parameters $(11,16)$. Regarding therapy discontinuation,
2 studies evaluated the rate of discontinuations of treatment or interruption of the radiation therapy due to side-effects. Wrbka et al. reported 2 therapy interruptions in the intervention- $v s .9$ in the control group and found a therapy improvement (quality of life and stable or improved X-ray image) of $68 \%$ in the intervention- compared to $57.96 \%$ in the control group ( $p=$ not stated) (19). Another study found no significant advantage of the intervention group in relation to therapy interruptions. Martin et al. (16).

In these heterogeneous studies, some significant reductions in specific adverse events were observed. A comparison is difficult, as some of these are combined symptom complexes. With regard to treatment interruptions, two studies came to opposite conclusions. Overall, no recommendation can be made for enzyme therapy. 
Table IV. Characteristics of included studies.

\begin{tabular}{cccc}
\hline Reference/Type & $\begin{array}{c}\text { Cancer Type/ } \\
\text { N/Dropout }\end{array}$ & Intervention & Outcomes
\end{tabular}

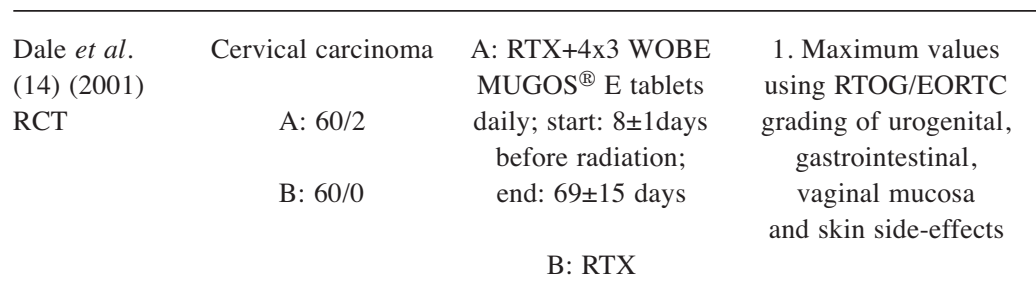

\begin{tabular}{|c|c|c|}
\hline \multirow[t]{3}{*}{$\begin{array}{l}\text { Dörr et al. } \\
\text { (11) (2007) } \\
\text { RCT }\end{array}$} & $\begin{array}{c}\text { Oropharynx } \\
\text { carcinoma }\end{array}$ & $\begin{array}{l}\text { A: } \mathrm{RTX}+3 \times 4 \text { WOBE } \\
\text { MUGOS }{ }^{\circledR} \text { E tablets } \\
\text { daily; start: } 3 \text { days }\end{array}$ \\
\hline & A: $36 / 4$ & before radiation; end: \\
\hline & B: $33 / 4$ & $\begin{array}{c}5 \text { days after last } \\
\text { fraction (total: up } \\
\text { to } 8 \text { weeks) }\end{array}$ \\
\hline & & B: RTX+Placebo \\
\hline
\end{tabular}

Gujral et al. Head and $\quad$ A: RTX $+3 \times 3$ WOBE (12) (2001) neck cancer $\quad$ MUGOS $^{\circledR}$ E tablets

RCT
1. Maximum and average value using RTOG/ EORTC grading of oral mucositis
1. A: (treatment arm) $0.93 \pm 0.52 v s$. B: $1.38 \pm 0.56$, significant $(p<0.001)$ for urogenital side-effects A: $1.12 \pm 0.64 v s$. B: $1.30 \pm 0.81$, not significant $(p=0.12)$ for gastrointestinal side-effects

A: $0.55 \pm 0.62 v s$. B: $0.85 \pm 0.82$, not significant $(p=0.10)$ for vaginal mucosa side-effects A: $0.97 \pm 0.82 v s$. B: $1.68 \pm 0.87$, significant $(p<0.001)$ for skin side-effects

1. Full analysis set A $v s$. B: no significant differences $(p=0.317)$ in maximum values; Full analysis set A vs. B: average value significant lower $(p=0.041)$

\section{Maximum values using RTOG/}

EORTC grading of mucositis, skin side-effects and dysphagia 2. Area under the curve for mucositis, skin side-effects and dysphagia 3. Time until occurrence of mucositis grade II, skin side-effects grade II and dysphagia grade I/II

4. Therapy outcome 8 weeks and 5-6 months after radiotherapy completion
1. A: $1.32 \pm 0.64 v s$. B: $2.24 \pm 0.60$, significant $(p<0.0001)$ for mucositis

A: $1.23 \pm 0.75 v s$. B: $2.39 \pm 1.10$, significant $(p<0.0001)$ for skin side-effects

A: $1.33 \pm 0.63 v s$. B: $2.24 \pm 0.60$, significant $(p<0.0001)$ for dysphagia

2. A: $5.4 \pm 3.6 v s$. B: $10.2 \pm 3.6$, significant $(p=0.0001)$ for mucositis

A: $3.9 \pm 2.9 v s .9 .5 \pm 3.9$, significant $(p=0.0001)$ for skin side-effects

A: $5.2 \pm 3.4 v s$. B: $10.1 \pm 3.6$, significant ( $p=0.0001$ ) for dysphagia

3. A: $6.9 \pm 0.8$ weeks $v s$. B: $5.7 \pm 1.2$, significant $(p=0.0014)$ for mucositis grade II

A: $6.6 \pm 1.6 v s$. B: $5.7 \pm 1.4$, significant $(p=0.0048)$ for skin side-effects

A: $5.2 / 7.3 \pm 1.5 / 0.8 v s$. B: $3.6 / 6.1 \pm 0.5 / 1.3$, significant $(p=0.0092 / 0.0064)$ for dysphagia grade I/II

4. A: lost for evaluation $n=3$; complete/ good response $n=32 / 16$; moderate response $\mathrm{n}=1$; poor/no response/progression $\mathrm{n}=1$ vs. B: lost for evaluation $n=4$; complete/ good response $n=23 / 15$; moderate response $\mathrm{n}=5$; poor/no response/progression $\mathrm{n}=0$, not significant $(p=0.23)$ for outcome 8 weeks after radiotherapy

A: lost for evaluation $n=15$; complete/ good response $n=25 / 7$; moderate

response $\mathrm{n}=1$; poor/no response/progression $\mathrm{n}=5$ vs. B: lost for evaluation $\mathrm{n}=18$; complete/good response $n=17 / 9$; moderate response $\mathrm{n}=1$; poor/no response/progression $\mathrm{n}=2$, not significant $(p=0.76)$ for outcome 5-6 months after radiotherapy 
Table IV. Continued

\begin{tabular}{|c|c|c|c|}
\hline Reference/Type & $\begin{array}{c}\text { Cancer Type/ } \\
\text { N/Dropout }\end{array}$ & Intervention & Endpoints \\
\hline $\begin{array}{l}\text { Martin et al. } \\
\text { (16) (2002) } \\
\text { RCT }\end{array}$ & $\begin{array}{c}\text { Pelvic } \\
\text { malignancy } \\
\text { A: } 28 / 4 \\
\text { B: } 28 / 4\end{array}$ & $\begin{array}{l}\text { A: RTX+3x4 WOBE } \\
\text { MUGOS }{ }^{\circledR} \text { tablets daily; } \\
\text { start: } 3 \text { days before } \\
\text { radiation; end: last } \\
\text { day of radiation } \\
\text { B: RTX+Placebo }\end{array}$ & $\begin{array}{l}\text { 1. Frequency and level } \\
\text { of the toxicity } \\
\text { parameters: diarrhea, } \\
\text { nausea, vomiting, } \\
\text { fatigue and } \\
\text { epitheliolysis using } \\
\text { the CTC/RTOG } \\
\text { grading } \\
\text { 2. Additionally required } \\
\text { medication } \\
\text { 3. Interruption/ } \\
\text { termination of } \\
\text { radiation therapy }\end{array}$ \\
\hline
\end{tabular}

$\begin{array}{lr}\begin{array}{l}\text { Stauder } \text { et al. } \\ \text { (21) (1991) }\end{array} & \begin{array}{r}\text { Abdominal } \\ \text { cancer }\end{array} \\ \text { RCT } & \text { A: } 36 / \mathrm{N} / \mathrm{A} \\ & \text { B: } 32 / \mathrm{N} / \mathrm{A}\end{array}$

B: $32 / \mathrm{N} / \mathrm{A}$

A: RTX+5-15 (10.6 \pm 4.0$)$ WOBE MUGOS ${ }^{\circledR}$ tablets daily, for the first two weeks; $10.3 \pm 4.0$ from day 14 to day 35

\section{B: RTX}

1. Influences on the intensity of radiation treatment

2. Influences on general status (fatigue, appetite, headache, nausea, vomiting, diarrhea, skin symptoms)

3. Influences on radio therapy side-effects 4. Influences on supplementary medication 5. Global evaluation of enzyme therapy compatibility by physician and patient

\begin{tabular}{|c|c|c|}
\hline \multirow[t]{4}{*}{$\begin{array}{l}\text { Tan et al. } \\
\text { (17) (2018) } \\
\text { RCT }\end{array}$} & $\begin{array}{l}\text { Hematologic } \\
\text { tumor }\end{array}$ & $\begin{array}{l}\text { A: third molar } \\
\text { extraction } \\
+3 \times 3000 \text { units }\end{array}$ \\
\hline & A: $36 / \mathrm{N} / \mathrm{A}$ & $\begin{array}{l}\text { Bromelain; start: } \\
1 \text { day before }\end{array}$ \\
\hline & B: $36 / \mathrm{N} / \mathrm{A}$ & $\begin{array}{c}\text { extraction; end: } \\
3 \text { days after extraction }\end{array}$ \\
\hline & & $\begin{array}{l}\text { B: third molar } \\
\text { extraction + cold- } \\
\text { hot compress }\end{array}$ \\
\hline
\end{tabular}

1. None/mild diarrhea A: $43 \%$ vs. B: $64 \%$; moderate/ severe $57 \%$ vs. $36 \%$, not significant $(p=0.11)$, no differences in average values ( $p$ not given) none/mild nausea A: $93 \%$ vs. B: $93 \%$; moderate/ severe $7 \%$ vs. 7\%, not significant ( $p$ not given) none/mild vomiting A: $100 \%$ vs. B: $96 \%$, moderate/ severe $0 \%$ vs. $4 \%$, not significant ( $p$ not given) none/mild fatigue A: $82 \% v s$. B: $93 \%$; moderate/ severe $18 \%$ vs. $7 \%$, not significant $(p=0.23)$, no differences in average values ( $p$ not given) none/mild epitheliolysis A: 75\% vs. B: $89 \%$; moderate/ severe $25 \%$ vs. $11 \%$, not significant $(p=0.16)$, no differences in average values ( $p$ not given) 2. A: 29 vs. 19, no statistical analysis 3. A: 2.44 vs. 1.46 days, no statistical analysis

1. Single dose (Gy) at the beginning, after 2 weeks, after 5 weeks A: $1.95 \pm 0.11,1.95 \pm 0.11,1.95 \pm 0,11 v s$. B: $1.81 \pm 0.45,1.88 \pm 0.25,1.88 \pm 0.26$, no statistical analysis Total dose (Gy) after 2 weeks and 5 weeks A: $19.70 \pm 3.88,54.20 \pm 13.60 v s$. B: $19.80 \pm 3.50$, $46.70 \pm 7.68$, no statistical analysis

2. Sum scores of the parameters after 0-, 2- and 5-weeks A: 0.04, 1.36, 1.42 vs. B: 0.41, $2.25,2.32$, no statistical analysis, conversion into percentage values referred to a maximum value of $100 \%$ after 0-, 2- and 5-weeks A: 0.12, 4.12, 4.30

$v s$. B: 1.24, 6.82, 7.03, no statistical analysis leading to an aggravation in A: $5.5 \%$ vs. B: $11.4 \%$, no change in A: $94.5 \%$ vs. B: $88.6 \%$

3. Mean start of radiotherapy side-effects in days

A: $12.8 \pm 9.7 v s$. B: $24.6 \pm 14.2$, no statistical analysis severity of side-effects (score 1-3) A: $1.77 \pm 0.77 v s$. B: $1.88 \pm 0.62$, no statistical analysis

4. A: 102x supplementary medication $v s$. B: $125 x$, no statistical analysis

5. Average therapy tolerance evaluated by physician A: $1.57 \pm 0.88 v s$. B: $1.38 \pm 0.86$; by patient A: $1.75 \pm 1.13 v s$. B: $1.41 \pm 0.86$ average therapy outcome evaluated by physician A: $1.94 \pm 0.79 v s$. B: $1.22 \pm 0.54$; by patient A: $1.89 \pm 0.85 v s$. B: $1.22 \pm 0.54$

1. Day 1 A: $5.35 \pm 1.14$ vs. B: $6.06 \pm 1.23$, significant $(p=0.013)$; day 3 A: $4.06 \pm 1.13 v s$. B: $4.73 \pm 1.25$, significant $(p=0.019)$; day $7 \mathrm{~A}: 2.23 \pm 1.02$ vs. B: $2.76 \pm 1.17$, significant $(p=0.044)$

2. Day 1 A: $2.23 \pm 0.34 v s$. B: $2.85 \pm 0.43$, significant $(p<0.0001)$; day 3 A: $1.23 \pm 0.13 v s$. B: $1.98 \pm 0.27$, significant $(p<0.0001)$; day 7 A: $0.23 \pm 0.11$ vs. B: $1.01 \pm 0.37$, significant $(p<0.0001)$

3. Day 1 A: $2.15 \pm 0.34 v s$. B: $2.76 \pm 0.53$, significant $(p<0.0001)$; day 3 A: $1.16 \pm 0.33 v s$. B: $1.83 \pm 0.45$, significant $(p<0.0001)$; day 7 A: $0.43 \pm 0.12$ vs. B: $1.16 \pm 0.27$, significant $(p<0.0001)$ 
Table IV. Continued

\begin{tabular}{|c|c|c|c|c|}
\hline Reference/Type & $\begin{array}{l}\text { Cancer Type/ } \\
\text { N/Dropout }\end{array}$ & Intervention & Endpoints & Outcomes \\
\hline & & & & $\begin{array}{r}\text { 4. Food A: } 5.76 \pm 2.78 v s . \text { B: } 7.96 \pm 2.18, \\
\text { significant }(p=0.0004) \\
\text { Language A: } 1.17 \pm 0.63 v s . \text { B: } 2.57 \pm 0.93, \\
\text { significant }(p<0.0001) \\
\text { Feeling A: } 0.83 \pm 0.36 v s . \text { B: } 1.44 \pm 0.76, \\
\text { significant }(p<0.0001) \\
\text { Swelling A: } 3.28 \pm 1.57 v s . \text { B: } 4.76 \pm 2.06, \\
\text { significant }(p<0.0001) \\
\text { Pain A: } 4.16 \pm 2.01 \text { vs. B: } 6.23 \pm 1.01, \text { significant }(p<0.0001) \\
\text { Nausea A: } 0.21 \pm 0.12 v s . \text { B: } 0.91 \pm 0.21, \\
\text { significant }(p<0.0001) \\
\text { Daily living A: } 1.38 \pm 0.34 v s . \text { B: } 3.38 \pm 0.54, \\
\text { significant }(p<0.0001)\end{array}$ \\
\hline
\end{tabular}

\begin{abstract}
Vinzenz
et al. (13)

(1992)

RCT
\end{abstract}

Head and

-

A: $19 / \mathrm{N} / \mathrm{A}$

B: $20 / \mathrm{N} / \mathrm{A}$

Wrbka et al. (19) (1978) RCT

Kasseroller et al. (18) (2003) RCT

$\begin{array}{lc}\begin{array}{l}\text { Lahousen } \\ \text { et al. }(23)\end{array} & \begin{array}{c}\text { Ovarian } \\ \text { carcinoma }\end{array} \\ \begin{array}{l}\text { (1995) } \\ \text { RCT }\end{array} & \text { A: } 24 / \mathrm{N} / \mathrm{A} \\ \begin{array}{l}\text { (Only side- } \\ \text { effects and }\end{array} & \text { B: } 12 / \mathrm{N} / \mathrm{A} \\ \begin{array}{l}\text { tolerance are } \\ \text { considered) }\end{array} & \text { C: } 23 / \mathrm{N} / \mathrm{A}\end{array}$

Mammary

cancer

A: $44 / \mathrm{N} / \mathrm{A}$

B: $44 / \mathrm{N} / \mathrm{A}$
A: RTX+3x 5 WOBE MUGOS $^{\circledR}$ tablets daily

$$
\text { B: RTX }
$$

1. Maximum value of mucositis (stage I, II, III)

2. First occurrence of mucositis

1. Tolerance of cytostatic treatment and survival time 2. Quality of life
A: $25 / \mathrm{N} / \mathrm{A}$
B: 26/N/A

A: CDT $+3 \times 5$ Wobenzym ${ }^{\circledR}$ tablets daily over a period of 6.5 weeks

\section{B: CDT+Placebo}

A: CTX+3x2 WOBE MUGOS $^{\circledR}$ tablets daily on day two to 7 of every CTX cycle

B: CTX+3x10 WOBE MUGOS ${ }^{\circledR}$ dragees daily on day two to

7 of every CTX cycle

C: CTX + Placebo
3. Success of therapy via radiological findings and quality of life

1. Volume of the affected arm after axillary dissection

2. Skinfold thickness compared to the baseline as fibrosis parameter 3. Skin tension compared to the baseline

1. Subjective global assessments:

Effectiveness and tolerability of enzyme therapy

2. Karnofsky Index

3. Therapeutic success of the oncological basic therapy
1. Stage I A: $21.4 \% v s$. B: $0 \%$; stage II A: $68.4 \% v s$. B: $55 \%$; stage III A: $10.5 \% v s$. B: $45 \%$; average value A: $1.9 \pm 0.56$ vs. $2.5 \pm 0.59$, significant ( $p=0.014$, chi square test); in B were significantly more patients in stage III ( $p=0.019$, exact fisher test)

2. Average value A: $9.1 \pm 4.9$ days $v s$. B: $13 \pm 4.1$, median A: 9.0 vs. B: 12.5

1. Therapy interruptions A: 2 vs. B: 9; average survival time (only patients with a survival time $>6$ months included) A: 20 months vs.

B: 16.3 , no statistical evaluation

2. Patients with a survival time $>6$ months, higher quality of life in A: $81.9 \%$ (class I, II) vs. B: $73.3 \%$, no statistical evaluation

3. Recovery in A: $68 \%$ vs. B: $57.69 \%$, no statistical evaluation

1. Mann-Whitney statistics for volume reduction;

A: Baseline 2483.0 and Visit $42275.1 v s$. B:

2420.1 and 2225.7, not significant ( $p$ not given)

2. "Upper ill arm" A: Baseline $7.4 \mathrm{~mm}$ and Visit 4 $4 \mathrm{~mm}$ vs. B: $6.7 \mathrm{~mm}$ and $3.4 \mathrm{~mm}$, "slight advantage for A" ( $p$ not given); similar trend for lower arm and third finger

3. A: Baseline 2.0 and Visit 40.4 vs. B: 1.8 and 0.5 , significant ( $p$ not given)

1. Subjective evaluation of efficacy and tolerability; physician evaluation in all patients "very good"; patient evaluation in all patients except one patient with undesirable side-effects "very good", one patient "poor" in B

2. $100 \%$ throughout; except for one patient at the end 3. Subjective evaluation of efficacy; physician evaluation in all 59 patients "very good"; patient evaluation in 58 patients "very good", of therapy: $80 \%$; here no indication to which intervention arm the patient belongs 1 patient "poor" in B 
Table IV. Continued

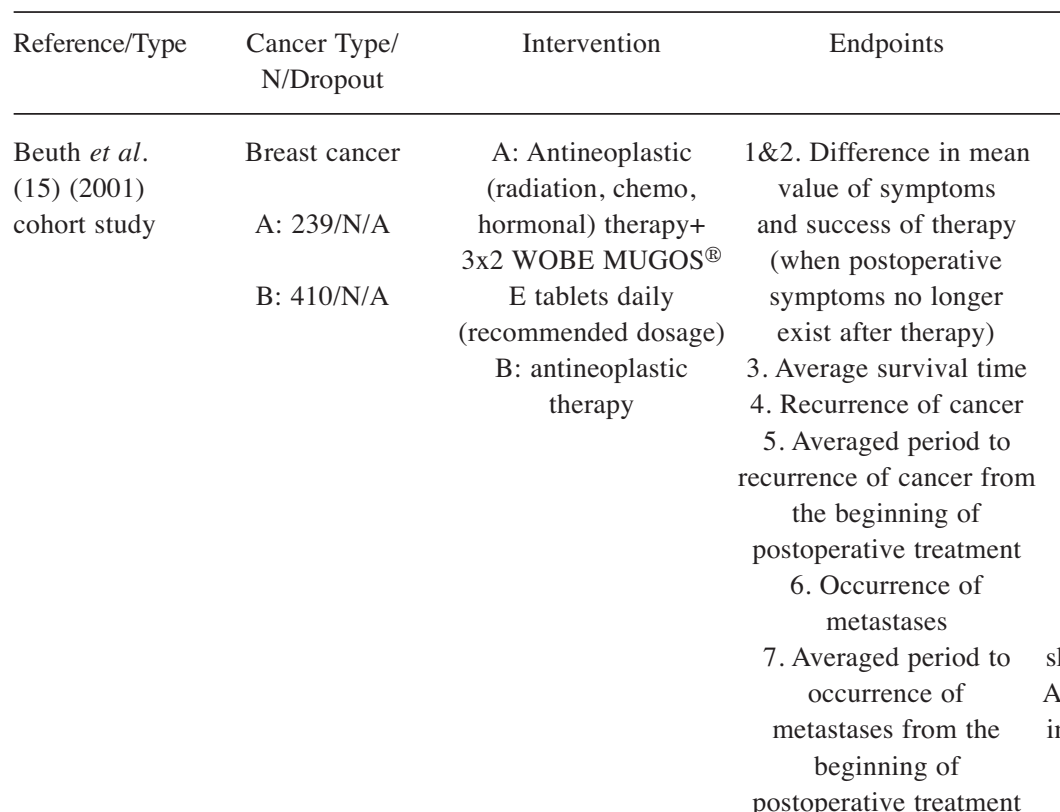

postoperative treatment

Popiela et al. (20) (2001)

cohort study

\section{Colorectal cancer}

A: $587 / \mathrm{N} / \mathrm{A}$

B: $597 / \mathrm{N} / \mathrm{A}$
A: Antineoplastic therapy $+3 \times 2$ WOBE MUGOS ${ }^{\circledR}$ E tablets daily (recommended dosage)

B: Antineoplastic therapy
1. Disease and treatmentspecific symptoms during and after antineoplastic therapy in comparison to baseline

2. Tolerance and safety of cancer therapy,

"tolerance very good" 3. Changes in mean value of symptoms

4. Patients without any symptoms in \%

5. Relevant reduction of treatment damage from chemo or radiotherapy

6. Differences in

Performance Index 7. Differences in Karnofsky Index
1\&2. Gastrointestinal A: (mean value difference) 0.27 vs. B: 0.11 , significant $(p=0.005)$

A: (Success of therapy) $42 \% v s$. B: $36 \%$, significant $(p=0.042)$ mental A: $0.26 v s$. B: 0.12 , significant $(p=0.005)$

A: $24 \% v s$. B: $24 \%$, not significant $(p=0.707)$ dyspneic A: $0.20 v s$. B: -0.22 , significant $(p=0.012)$

A: $31 \%$ vs. B: $17 \%$, not significant $(p=0.056)$ headache A: $0.44 v s$. B: 0.08 , significant $(p=0.036)$ A: $50 \%$ vs. B: $29 \%$, not significant $(p=0.315)$ tumor pain A: $0.48 v s$. B: 0.68 , not significant $(p=0.272)$

A: $65 \%$ vs. B: $60 \%$, not significant $(p=0.483)$ cachexia A: $0.66 v s$. B: -0.50 , significant $(p=0.002)$

A: $65 \% v s$. B: $7 \%$, significant $(p=0.008)$ skin reactions A: $0.65 v s$. B: 0.15 , significant $(p=0.006)$ A: $38 \%$ vs. B: $60 \%$, significant for control arm $(p=0.006)$ infections A: $0.50 v s$. B: 0.24 , not significant $(p=0.125)$

A: $48 \%$ vs. B: $24 \%$, not significant $(p=0.597)$

3. Deceased A: $1.26 \%$ vs. B: $2.68 \%$ in the postoperative period, no statistical evaluation average survival time A: 1840 days (5.04 years) vs. B: 1820 days (4.99 years), not significant (plog-rank $=0.0787$ )

4. Recurrence A: $2.50 \%$ vs. B: $6.34 \%$, no statistical evaluation

5. Averaged period A: 1818 days (4.98 years) vs.

B: 1702 days (4.66 years), significant $(p=0.0055)$

6. Occurrence A: $5.04 \% v s$. B: $7.58 \%$, no statistical evaluation

7. Averaged period A: 1738 days (4.76 years) vs.

B: 1665 days ( 4.56 years), significant $(p=0.0475)$

Mann-Whitney statistics: 0.36 medium-sized inferiority, 0.44 small inferiority, 0.5 no difference,

0.56 small superiority, 0.64 medium-sized superiority, 0.71 large superiority

Mono subgroup: patients have not received any other complementary therapies

Compl subgroup: patients of both arms have received further complementary medicine

1. Mono subgroup: 0.6077, 95\% CI: 0.5535-0.6619, $(p<0.0001)$; A: small superiority

Compl subgroup: 0.5224, 95\% CI: 0.4756-0.5692, $(p=0.3486)$; no difference

2. Mono subgroup: $0.7471,95 \%$ CI: 0.7054-0.7889, $(p<0.0001) ; \mathrm{A}:$ large superiority

Compl subgroup: 0.5865, 95\% CI: 0.5455-0.6275, $(p<0.0001) ; \mathrm{A}$ : small superiority

3. Mono subgroup: $0.6478,95 \%$ CI: $0.5898-0.7058$, $(p<0.0001)$; A: medium-sized superiority

Compl subgroup: 0.5040, 95\% CI: 0.4548-0.5532, ( $p=0.8727)$; no difference

4. Mono subgroup: $0.5440,95 \%$ CI: $0.4950-0.5929$, $(p=0.0798)$; no difference Compl subgroup: 0.5570 , 
Table IV. Continued

\begin{tabular}{|c|c|c|c|c|}
\hline Reference/Type & $\begin{array}{c}\text { Cancer Type/ } \\
\text { N/Dropout }\end{array}$ & Intervention & Endpoints & Outcomes \\
\hline & & & $\begin{array}{c}\text { 9. Survival time } \\
\text { analysis }\end{array}$ & 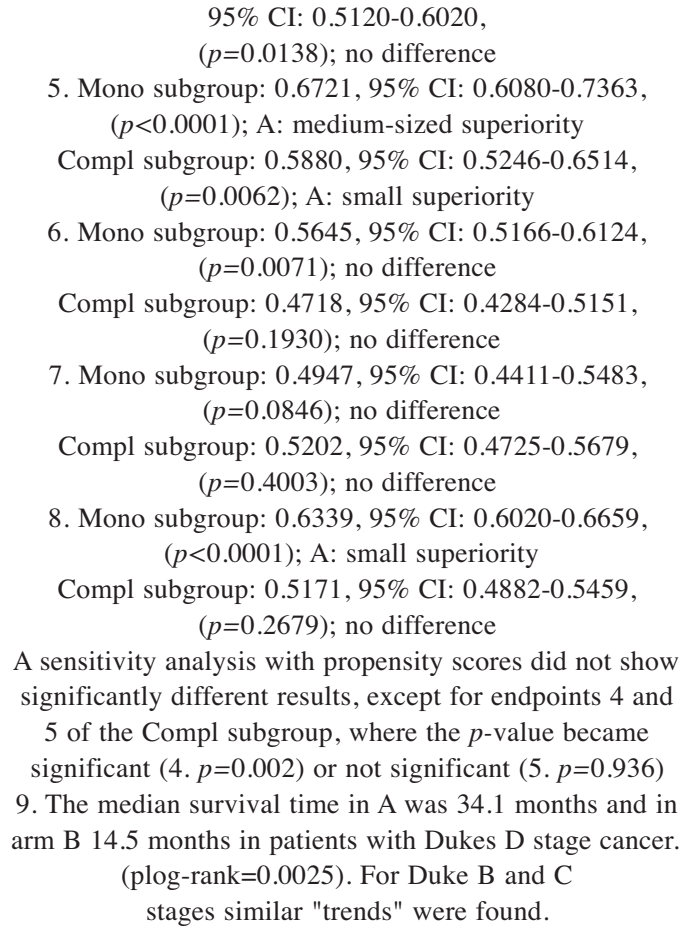 \\
\hline
\end{tabular}

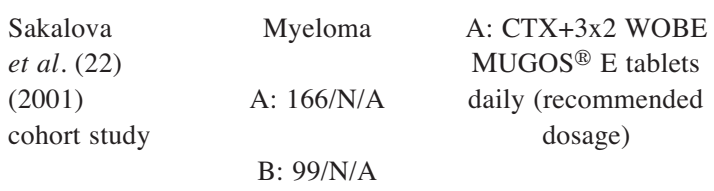

B: CTX
1. Disease-specific survival following diagnosis 2. Response to chemotherapy, evaluated in 4 categories according to the SWOG criteria: complete remission, partial remission, stable findings, no reaction

3. Remission period 4. Side-effects
1. Stage III patients A: median 83 months (95\% CI: 50-117) vs. B: median 47 months (95\% CI: 32-62 months), significant difference $(p=0.0014)$, significant also in intention-to-treat analysis $(p=0.0342)$

Due to the small number of cases in stages I and II, no mean survival time can be quantified ( $p$-values are not significant here either); however, there is a significant result of lifetime extension for A across all stages. (adjusted for stage, $p=0.0003$ )

Median survival in patients with immediate response to chemotherapy $130 \mathrm{vs} .51$ months in patients with no response $(p=0.0000)$ all-cause mortality median survival advantage in A: 33 months in stage III $(p=0.0059)$, even if adjusted for stage $(p=0.0039)$ multivariate analysis: median reduction of $60 \%$ in risk of death at all stages by use of oral enzymes $(p=0.011)$

2. Percentage of patients with complete, partial remission and stable findings in all stages (I, II, III) in A: $97.6 \%$ vs. B: $69.7 \%$, significant $(p=0.001)$; proportion of patients in stage III without response to chemotherapy A: $3.7 \% v s$. B: $38.9 \%$, significant $(p \leq 0.001)$

3. Duration of initial remission/stable state in stage

II and III patients significantly longer in A than in B ( $p$ not given); in stage III an average of 37.7 months in A vs. 11.6 months in B ( $\mathrm{p}$ not given)

4. In total, there were 34 therapy side-effects, of which 6 were associated with enzyme therapy. All 6 side-effects were related to gastrointestinal complaints 
Table IV. Continued

\begin{tabular}{|c|c|c|c|c|}
\hline Reference/Type & $\begin{array}{l}\text { Cancer Type/ } \\
\text { N/Dropout }\end{array}$ & Intervention & Endpoints & Outcomes \\
\hline $\begin{array}{l}\text { Kesztele } \text { et al. } \\
(24) \text { (1976) } \\
\text { single-arm } \\
\text { study } \\
\text { (Only side- } \\
\text { effects are } \\
\text { considered) }\end{array}$ & $\begin{array}{l}\text { Bronchial } \\
\text { carcinoma } \\
\text { 73/N/A }\end{array}$ & $\begin{array}{l}\text { Antineoplastic therapy } \\
+2 \times 5 \text { WOBE MUGOS } \\
\text { tablets dissolved in } \\
\text { water as clysma, three- } \\
\text { week break, further } \\
\text { application for } 5 \text { days }\end{array}$ & $\begin{array}{l}\text { 1. Tolerance/ } \\
\text { side-effects of the } \\
\text { enzyme therapy }\end{array}$ & $\begin{array}{l}\text { 1. There were no harmful side-effects, except for occasional } \\
\text { perianal eczema, which makes the treatment risk-free. }\end{array}$ \\
\hline $\begin{array}{l}\text { Petru } \text { et al. } \\
(25)(2010) \\
\text { single-arm } \\
\text { study } \\
\text { (Only side- } \\
\text { effects are } \\
\text { considered) }\end{array}$ & $\begin{array}{l}\text { Breast cancer } \\
\text { 57/N/A }\end{array}$ & $\begin{array}{l}\text { CTX }+3 \times 2 \text { WOBE } \\
\text { MUGOS }{ }^{\circledR} \text { dragees daily } \\
\text { during therapy, except } \\
\text { on the first day of CTX }\end{array}$ & $\begin{array}{l}\text { 1. Tolerance/side- } \\
\text { effects of the } \\
\text { enzyme therapy }\end{array}$ & $\begin{array}{l}\text { 1. Enzymes were well tolerated by } 52 \text { patients, three patients } \\
\text { complained of new moderate upper abdominal complaints } \\
\text { two patients complained of moderate meteorism }\end{array}$ \\
\hline
\end{tabular}

A: Treatment arm; B: comparison arm; RTOG: Radiation Therapy Oncology Group; EORTC: European Organisation for Research and Treatment of Cancer; CTC: Common Toxicity Criteria; PoSSe: Post-operative Symptom Severity; CDT: combined decongestive therapy (lymphatic drainage on the neck, arm and thorax, consecutive bandaging of the affected arm, specially designed exercises and skin care); WOBE MUGOS® (E): 100 mg Papain, 40 mg Trypsin, 40 mg Chymotrypsin; Wobenzyme: 100mg Pankreatin, 60 mg Papain, 45 mg Bromelain, 24 mg Trypsin, 10 mg Lipase, $10 \mathrm{mg}$ Amylase, $1 \mathrm{mg}$ a-Chymotrypsin, $50 \mathrm{mg}$ Rutoside; WOBE MUGOS ${ }^{\circledR}$ dragees: WOBE MUGOS® (Lahousen): $40 \mathrm{mg}$ Trypsin from pancreas, $40 \mathrm{mg}$ Chymotrypsin from pancreas, $100 \mathrm{mg}$ Papain, $40 \mathrm{mg}$ Hydrolysate from calf thymus; WOBE MUGOS® dragees: $16 \mathrm{mg}$ Proteolytic enzymes from fractionated hydrolysates from bovine pancreas, $8 \mathrm{mg}$ Calf thymus, $8 \mathrm{mg}$ Pisum sativum, $8 \mathrm{mg}$ Lens eculenta, $4 \mathrm{mg}$ Papytoin; SWOG criteria: Southwest Oncology criteria for assessing tumor response to treatment.

Tolerability of cancer treatment. We assessed 2 RCTs and one cohort study examining the tolerability of the cancer therapy. Popiela et al. analyzed the disease- and treatmentspecific symptoms (summarized symptom complex consisting of 19 points) of 1,242 patients during and after antineoplastic therapy compared to the previously assessed baseline using Mann-Whitney tests. There was a slight superiority of the enzyme therapy between the arms (MWS statistics $0.6077 ; p<0.0001)$. The tolerability and safety of cancer therapy, assessed by the physician using a five-point ordinal scale, resulted in a strong superiority of the intervention group (MWS statistics 0.7471; $p<0.0001$ ). Changes in mean value of existing symptoms also became significant with a mean superiority of the intervention group (MWS statistics 0.6478; $p<0.0001)$. The endpoint "Proportion of patients without therapy complaints" showed no significant difference between the groups (MWS statistics $0.5440 ; p=0.0798)$. There was a significant reduction of treatment side-effects caused by chemo- and radiotherapy with a mean superiority of the intervention group (MWS statistics $0.6721 ; p<0.0001)$. The endpoint Performance Index and Karnofsky Index during therapy did not reveal any significant difference between the groups (20). Stauder et al. evaluated the influence of enzyme treatment on the dose of the radiation treatment, on the general status and on the sideeffects of radiotherapy. In this study, only total numbers are given, and no statistical evaluation was carried out for any endpoint. The authors state that a higher dose of radiation was tolerated in the intervention group and overall higher doses were applied in this group. They present numbers for the occurrence and severity of radiation side-effects and the average tolerance, but the results cannot be interpreted due to missing statistical analysis (21). Wrbka et al. $(\mathrm{N}=51)$ evaluated if additional enzyme administration improved tolerance of chemotherapy. On average, all patients, including a subgroup of patients, with a survival time of more than 6 months, received a higher number of chemotherapy transfusions (mean number of treatments 6.88 vs. 4.50; 11 vs. 3.37) (19).

In conclusion, enzyme therapy seems to have a benefit in terms of tolerability, improved adherence to the treatment protocol, but not with respect to symptom resolution and on physical fitness. However, the results are from two nonblinded RCT's and one cohort study, so further studies are needed for a final recommendation.

Response to treatment. Two RCTs and 1 cohort study assessed the endpoint therapy course. Gujral et al. $(\mathrm{N}=100)$ 
Table V. Excluded studies.

\begin{tabular}{lccc}
\hline Author & Year & Title & Reason for exclusion \\
\hline $\begin{array}{l}\text { J. Beuth, R. van Leendert, } \\
\text { B. Schneider and G. Uhlenbruck }\end{array}$ & 2013 & $\begin{array}{c}\text { Complementary medicine on side-effects of adjuvant } \\
\text { hormone therapy in patients with breast cancer }\end{array}$ & Multi preparation \\
$\begin{array}{l}\text { G. Uhlenbruck, R. Van Leendert, } \\
\text { B. Schneider and J. Beuth }\end{array}$ & 2010 & $\begin{array}{c}\text { Reduced side-effects of adjuvant hormone therapy in } \\
\text { breast cancer patients by complementary medicine }\end{array}$ & Multi preparation \\
\hline
\end{tabular}

found no significant difference in disease response, divided into complete/good-, moderate- and poor/no response, of their head- and neck cancer patients between intervention- and control group after 8 weeks $(p=0.23)$ and 5-6 months $(p=0.76)$ (12). Stauder et al. compared the influence of enzyme therapy on the cancer therapy of 68 patients. The assessment of treatment result was reported by the treating physician and patients divided into grades from 1 to 6 . There was a trend in favor of the control group, but no further statistical analysis was conducted (21). Sakalova et al. compared the response to chemotherapy of 265 patients with multiple myeloma. The proportion of patients in stage III who did not respond to chemotherapy was significantly lower in the intervention group (3.7\% vs. 38.9\%; $p \leq 0.001$ ) (22).

These 3 studies, with cancer entities differing from each other, came to heterogeneous conclusions. Patients with multiple myeloma showed a better response to therapy, while there was no improvement in head and neck cancer patients and even a (non-significant) trend in favor of the control group in patients with abdominal cancer. The evidence does not allow a recommendation for or against enzyme therapy.

Disease-specific survival, remission, cancer recurrence or metastases. One RCT and 3 cohort studies assessed the endpoint disease-specific survival, remission, cancer recurrence or metastases. Sakalova et al. compared the median survival time, time to recurrence of cancer or metastases in 265 patients with multiple myeloma. Patients in the subgroup of stage III cancers had a significant longer median survival time in the intervention group (83 months $v s .47$ months; $p=0.0014$ ), this corresponds to a lifetime gain of about 3 years. A significant stage-adjusted increase of lifetime across all stages could be proven in favor of the intervention group $(p=0.0003)$. Moreover, concerning the overall mortality (including nonmyeloma-related deaths) in stage III, the intervention group showed a median advantage of survival of 33 months over the control group $(p=0.0059)$. A multivariate analysis showed that the risk of death could be reduced by $60 \%(p=0.0011)$ due to enzyme therapy, taking various possible influences into account (stage, age etc.). The authors also came upon with a significant advantage of the intervention group for remission rate and stable findings across all stages (97.6\% vs. 69.7\%; $p=0.001)$ and the duration of initial remission or stable state in stage II and III patients (III: 37.7 months vs. 11.6 months; $p=$ not stated) (22). Popiela et al. found an advantage of survival time in the intervention group of their patients with colorectal cancer $(\mathrm{N}=1,242,34.1$ months $v s .14 .5$ months; plog-rank=0.0025) for patients with Dukes D cancer stage. The authors report similar trends in Dukes B and C stages (20). Wrbka et al. $(\mathrm{N}=51)$ showed a difference in survival time in the subgroup of patients with a survival time of more than 6 months (20 vs. 16.3 months for the intervention group; $p=$ not stated) (19). Another study ascertained no significant difference in mean survival time in the postoperative period between the two arms of their breast cancer patients $(\mathrm{N}=649)$. There was no statistical analysis in terms of overall recurrence of cancer and metastases in intervention- and control group. A significant difference was detected in the time to cancer recurrence or metastasis between intervention- and control group (1,818 days vs. 1,702 days; $p=0.0055$; metastasis 1,738 days $v s .1665$ days; $p=0.0475)(15)$.

With respect to impact on the development of the cancer, all studies supported a significant benefit of enzyme therapy. A negative influence or trend was not observed in any study. Due to some restrictions of the available studies, as mentioned in the discussion afterwards, no recommendation for enzyme therapy can be given. More high-quality studies are needed.

Side-effects of enzyme therapy. Five RCTs, 3 cohort studies and 2 single-arm studies assessed side-effects of enzyme therapy. Regarding oral application, Kasseroller et al., Beuth et al., Popiela et al., Sakalova et al. and Dale et al. reported mainly gastrointestinal complaints in their studies (like diarrhea and nausea) ranging from mild to moderate severity, which sometimes led to the discontinuation of the affected participants $(14,15,18,20,22)$. Surprisingly, in Dale et al. the patients in the control group tended to experience more symptoms (11.7\% vs. $31.6 \%, p=0.12)(14)$. Gujral et al. and Lahousen et al. could not detect any side-effects of enzyme therapy $(12,23)$.

Two further studies carried out the application of enzymes partially or completely parenterally. Kesztele et al. (single- 
arm, bronchial carcinoma) reported that enzyme enema was well tolerated and only single perianal eczema occurred (24). Petru et al. described only 3 patients with moderate upper abdominal pain and 2 patients with meteorism of their 57 participants (25).

Wrbka et al. evaluated the tolerability of enzyme therapy as oral dugs, enema and intrapleural application. In 67 patients $87.3 \%$ showed a good tolerance of the enema. In 4 patients, the application was limited due to sphincter weakness and about $12.7 \%$ (8 patients) discontinued the treatment due to gastrointestinal side-effects like meteorism, diarrhea and nausea. Out of 58 patients, $71.4 \%$ (30 patients) showed good tolerability for the oral formula, whereas about $28.6 \%$ (12 patients) discontinued the treatment and in about $27 \%$ no assessment was possible, because these subjects stopped taking the tablets of their own accord or provided incorrect information in the studies. Therefore, no result could be ultimately assessed. For the tolerability of the local intrapleural application data of 33 patients were available, $96.9 \%$ of these showed a good tolerability and only about $3.1 \%$ stopped the treatment (19). Regarding the side-effects of enzyme therapy, all studies did not have any higher-grade side-effects.

\section{Discussion}

The studies included are very heterogeneous in terms of design, dosage of oral enzymes, patient characteristics and cancer treatment. Accordingly, the results are also heterogeneous. It is noticeable that especially blinded studies come to non-significant trends or even no differences between the treatment groups.

Two out of 3 studies, 1 including patients having carcinoma of the oral cavity (13) and another with head and neck cancer (12), undergoing radiotherapy reported a benefit of enzyme therapy regarding (oral) mucositis. One of the 2 also described a beneficial effect on the duration of mucositis (12). This could be mainly explained by the antiinflammatory and fibrinolytic activity of enzymes, whereby toxic products are diminished more easily (13), or rather by a modulation of the anti-inflammatory enzyme cascades, like a reduction of the TGF-b levels and scavenging of free radicals (12). In contrast, 1 study involving patients with oropharyngeal carcinoma (11) did not show any difference in the maximum expression of mucositis - it has even been a significant advantage for the control group, as mucositis was more likely to occur earlier in the enzyme group (11). An earlier occurrence of mucositis in the intervention group was also mentioned in the study by Vinzenz et al. (13). Altogether, the diverging results seem to depend on the study design, since the unblinded studies show a positive effect or at least a trend in favor of the intervention group $(12,13)$, whereas the blinded study comes to an opposite result (11).
To sum up, despite some hypotheses on the molecular pathways triggered by proteolytic enzymes, the evidence on oral mucositis during radiotherapy does not support the clinical usage but even might speaks against it due to a risk of harm for the patients due to an earlier onset. Supplementary it should be mentioned that enzymes have not shown any benefit with regard to mucositis of the vaginal mucosa by patients with cervical carcinoma (14).

Radiodermatitis was evaluated in 5 studies, 3 of which showed a positive response to enzyme therapy $(12,14,15)$. The other 2 studies do not provide significant results for erythema of the skin, dryness or moist skin desquamation (11) and 1 of them showed even a non-significant trend towards less epitheliolysis in the control group (16). In one study, it has to be noted that a clear result in favor of control group turned to a result in favor of intervention group after adjustment with propensity score (15). Again, blinding might have an impact on the result, because the blinded studies showed no benefit. Overall, the results on dermatitis are heterogeneous and no recommendation can be derived.

Other specific side-effects of cancer treatment were assessed in 5 studies $(11,14-16,20)$ with mostly no difference between the intervention- and control group. Again the only blinded study on gastrointestinal side-effects is the least supporting of enzyme therapy, as it shows a trend to an advantage for the control group (16).

The 2 studies assessing quality of life in context of swelling and pain after wisdom tooth extraction (17) and in lung cancer patients (19) have serious methodological drawbacks. Another study dealt with lymphedema due to lymph node removal (18). This study did not show a significant difference - except for skin tension which was rated by the investigator. In summary all 3 studies concerning edema and quality of life have methodological drawbacks such as no information on drop-out/attrition, unclear/questionable randomization processes $(17,18)$, lack of correction for multiple testing, doubtful blinding (17) or no statistical evaluation at all (19). As a result, the evidence on quality of life, edema and swelling is insufficient.

Three studies assessing the influence of enzymes on the tolerability and safety of cancer treatment therapy report a trend to an improved treatment tolerability, based on a reduction of defined symptoms, improvement of safety/tolerability, number, occurrence and/ or intensity of adverse events (19-21). Yet, only one of them provides a statistical analysis (20). The study by Popiela et al. came to heterogeneous results in the subgroups. A relevant drawback of this study is that the patients also used diverse other CAM methods which seem to have influenced the results (20). Due to missing statistical evaluation and unclear differences in the groups at baseline in the other studies no conclusion on the effectiveness of proteolytic enzymes with respect to tolerability and safety can be made. 
The course of treatment was evaluated in 5 studies $(12,16$, $19,21,22)$, only one of which found a positive effect that was statistically supported. This study with multiple myeloma patients showed significantly fewer non-responders to the intervention group. Yet, there were significant differences at baseline between laboratory parameters, treatment regimens and the evaluation took place in only one subgroup. Furthermore, study patients were assessed in the control group, if they took enzymes for less than 6 months (22). In the study by Stauder et al. compatibility and therapy result were evaluated by physicians and patients in favor of the control group, without providing statistical data. The explanation for the negative effect on the intervention group given by the authors was the probably exaggerated expectation on enzyme therapy (21). Also with respect to compatibility, only unblinded studies are in favor of enzyme therapy while the only blinded study shows an opposite trend (16).

Four studies delivered results on disease-specific survival, remissions and the recurrence of cancer $(15,19,20,22)$. Two of them showed a significant advantage of survival for the intervention group $(20,22)$ and 1 of the 2 indicated additionally that therapy response and remission rate are superior in the intervention group (22). On the other hand, a study monitoring breast cancer patients showed no advantage in mean survival, but a significant difference in time to metastasis or cancer recurrence (15). The study of Wrbka et al. on patients with bronchopulmonary carcinomas stated that the survival time in the intervention group was slightly better, but did not provide any statistical data (19). Overall, the available studies show a benefit for enzyme therapy. But this result should be treated with caution, as it based on 3 cohort studies and an open randomized controlled trial from the 1970s. The methodological quality of the studies has several limitations, e.g., no blinding, relevant baseline differences and study protocols containing switches between the intervention and control group, so that an influence of certain co-factors cannot be ruled out. Moreover, most of the study results refer to subgroups out of all study participants.

Overall, enzyme therapy is considered as rather safe according to the present evidence. No serious side-effects occurred, and only slight gastrointestinal side-effects were described (12, 14, 15, 18-20, 22-25). However, one case of circulatory shock occurring in the Netherlands under enzyme tablets and injections is worth mentioning (26). One study evaluated the perioperative bleeding risk with enzyme therapy and compared it with diclofenac use. In this comparison, there was no increased risk of bleeding (27). Nevertheless, the manufacturers recommend discontinuation before a planned operation.

Limitations of this review. There are some limitations of this systematic review which have to be mentioned. First, we excluded studies concerning children or teenager and only analyzed studies with adult patients. Besides, only studies in English or German were included. This means that the search for enzymes in connection with the treatment of cancer can still be expanded in further research.

To the best of our knowledge, this is the only existing systematic review of enzyme therapies to date. Based on carefully constructed search strings, it reflects the current clinical state of science.

\section{Conclusion}

Despite several clinical studies, the evidence on supportive treatment with proteolytic enzymes is scarce due to serious methodological drawbacks of most studies. Accordingly, despite interesting hypotheses on molecular mechanisms which might explain positive effects on cancer disease and side-effects of treatment, no compelling final assessment can be reached. There are partially significant results in terms of mucositis, radiodermatitis, quality of life, tolerability of therapy, survival and metastasis with a profile of low sideeffects, mainly in the form of moderate gastrointestinal complaints. A negative influence on the basic therapy could not be observed in any study. Overall, no recommendation for or against enzyme therapy can be given. Stringently planned RCTs of high quality are mandatory.

\section{Conflicts of Interest}

The Authors report no conflicts of interest or financial ties to disclose. The Authors alone are responsible for the content and writing of this article.

\section{Authors' Contributions}

All authors met all of the following criteria: i) Substantial contributions to the conception or design of the work or the acquisition, analysis, or interpretation of data for the work. ii) Drafting the work or revising it critically for important intellectually content. iii) Final approval of the version to be published. iv) Agreement to be accountable for all aspects of the work in ensuring that questions related to the accuracy or integrity of any part of the work are appropriately investigated and resolved.

\section{Acknowledgements}

The work of Sabine Kutschan and Jennifer Dörfler was funded in parts (search of the literature, title-abstract screening) by the German Guideline "S3 Leitlinie Komplementärmedizin in der Behandlung von onkologischen PatientInnen (Registernummer 032 - 055OL)" funded by the German Cancer Aid (Fördernummer 11583) within the German Guideline Program in Oncology.

\section{References}

1 Söllner W, Zingg-Schir M, Rumpold G and Fritsch P: Attitude toward alternative therapy, compliance with standard treatment, 
and need for emotional support in patients with melanoma. Arch Dermatol 133(3): 316-321, 1997. PMID: 9080891. DOI: 10.1001/archderm.1997.03890390054007

2 Huebner J, Muenstedt K, Prott FJ, Stoll C, Micke O, Buentzel J, Muecke R and Senf B: Online survey of patients with breast cancer on complementary and alternative medicine. Breast Care (Basel) 9(1): 60-63, 2014. PMID: 24803889. DOI: 10.1159/ 000360381

3 Latha B, Ramakrishnan KM, Jayaraman V and Babu M: Action of trypsin:chymotrypsin (Chymoral forte DS) preparation on acute-phase proteins following burn injury in humans. Burns 23(Suppl 1): S3-S7, 1997. PMID: 9177894. DOI: 10.1016/ s0305-4179(97)90093-0

4 Takahashi H, Sawai H, Funahashi H, Matsuo Y, Yasuda A, Ochi N, Sato M, Okada Y and Takeyama H: Antiproteases in preventing the invasive potential of pancreatic cancer cells. JOP 8(4 Suppl): 501-508, 2007. PMID: 17625307.

5 Kos J, Werle B, Lah T and Brunner N: Cysteine proteinases and their inhibitors in extracellular fluids: markers for diagnosis and prognosis in cancer. Int J Biol Markers 15(1): 84-89, 2000. PMID: 10763147.

6 Viswanatha Swamy AH and Patil PA: Effect of some clinically used proteolytic enzymes on inflammation in rats. Indian $\mathrm{J}$ Pharm Sci 70(1): 114-117, 2008. PMID: 20390096. DOI: 10.4103/0250-474X.40347

7 Sinclair RD and Ryan TJ: Proteolytic enzymes in wound healing: the role of enzymatic debridement. Australas J Dermatol 35(1): 35-41, 1994. PMID: 7998898. DOI: 10.1111/j.14400960.1994.tb01799.x

8 Methodology checklists. Available at: https://www. sign.ac.uk/what-we-do/methodology/checklists/ [Last accessed on April 26th, 2021]

9 Oxford Centre for Evidence-Based Medicine: Levels of Evidence (March 2009). Available at: https://www.cebm.ox. ac.uk/resources/levels-of-evidence/oxford-centre-for-evidencebased-medicine-levels-of-evidence-march-2009 [Last accessed on April 26th, 2021]

10 German Guideline Program in Oncology (GGPO). Available at: https://www.leitlinienprogramm-onkologie.de/english-language/ [Last accessed on April 26th, 2021]

11 Dörr W, Herrmann T and Study Group: Efficacy of Wobe-Mugos E for reduction of oral mucositis after radiotherapy: results of a prospective, randomized, placebo-controlled, triple-blind phase III multicenter study. Strahlenther Onkol 183(3): 121-127, 2007. PMID: 17340069 . DOI: 10.1007/s00066-007-1634-0

12 Gujral MS, Patnaik PM, Kaul R, Parikh HK, Conradt C, Tamhankar CP and Daftary GV: Efficacy of hydrolytic enzymes in preventing radiation therapy-induced side effects in patients with head and neck cancers. Cancer Chemother Pharmacol 47(Suppl): S23-S28, 2001. PMID: 11561868. DOI: 10.1007/s002800170005

13 Vinzenz K and Stauder U: Die Therapie der radiogenen Mukositis mit Enzymen. Chirurgische Therapie von Kopf-Hals-Karzinomen: 299-314, 2020. DOI: 10.1007/978-3-7091-9087-6_34

14 Dale PS, Tamhankar CP, George D and Daftary GV: Comedication with hydrolytic enzymes in radiation therapy of uterine cervix: evidence of the reduction of acute side effects. Cancer Chemother Pharmacol 47(Suppl): S29-S34, 2001. PMID: 11561869. DOI: $10.1007 / \mathrm{s} 002800170006$

15 Beuth J, Ost B, Pakdaman A, Rethfeldt E, Bock PR, Hanisch J and Schneider B: Impact of complementary oral enzyme application on the postoperative treatment results of breast cancer patients - results of an epidemiological multicentre retrolective cohort study. Cancer Chemother Pharmacol 47(Suppl): S45-S54, 2001. PMID: 11561873. DOI: 10.1007/s002800170009

16 Martin T, Uhder K, Kurek R, Roeddiger S, Schneider L, Vogt H, Heyd R and Zamboglou N: Does prophylactic treatment with proteolytic enzymes reduce acute toxicity of adjuvant pelvic irradiation? Results of a double-blind randomized trial. Radiotherapy and Oncology 65(1): 17-22, 2019. DOI: 10.1016/ S0167-8140(02)00192-5

17 Tan Y and Li P: Bromelain has significant clinical benefits after extraction of the third molar during chemotherapy in patients with hematologic tumor. Oncol Lett 15(3): 2962-2966, 2018. PMID: 29435025. DOI: 10.3892/ol.2017.7673

18 Kasseroller R and Wenning HG: Efficacy and tolerability of proteolytic enzymes as an anti-inflammatory agent in lymphoedema after axillary dissection due to mammary cancer. EJLRP 10(37-38): 18-26, 2003.

19 Wrbka E and Kondras B: Unterstuetzung der chemotherapie inoperabler bronchopulmonaler karzinome durch proteolytische fermente. Wien Med Wochenschr 128(5): 153-158, 1978.

20 Popiela T, Kulig J, Hanisch J and Bock PR: Influence of a complementary treatment with oral enzymes on patients with colorectal cancers - an epidemiological retrolective cohort study. Cancer Chemother Pharmacol 47(Suppl): S55-S63, 2001. PMID: 11561874. DOI: $10.1007 / \mathrm{s} 002800170010$

21 Stauder G, Beaufort F and Streichhan P: Strahlentherapeutische Nebenwirkungen bei Abdominalkrebspatienten und deren Reduktion durch hydrolytische Enzympräparate. Dtsch Zschr Onkol 23: 7-16, 1991.

22 Sakalova A, Bock PR, Dedik L, Hanisch J, Schiess W, Gazova S, Chabronova I, Holomanova D, Mistrik M and Hrubisko M: Retrolective cohort study of an additive therapy with an oral enzyme preparation in patients with multiple myeloma. Cancer Chemother Pharmacol 47(Suppl): S38-44, 2001. PMID: 11561871. DOI: $10.1007 / \mathrm{s} 002800170008$

23 Lahousen M: Modification of liver parameters by adjuvant administration of proteolytic enzymes following chemotherapy in patients with ovarian carcinoma. Wien Med Wochenschr 145(24): 663-668, 1995. PMID: 8585220.

24 Kesztele V, Hürbe E and Wischin W: Erfahrungen mit proteolytischen Enzymen beim Bronchuskarzinom. Wien Med Wochenschr 126: 412-414, 1976.

25 Petru E, Stranz B and Petru C: Effects of proteolytic enzyme therapy with Wobe Mugos against chemotherapy-induced toxicity in breast cancer patients - results of a pilot study. Wien Med Wochenschr 160(19-20): 513-516, 2010. PMID: 20972712. DOI: $10.1007 / \mathrm{s} 10354-010-0835-9$

26 de Smet PA, Pegt GW and Meyboom RH: Acute circulatory shock following administration of the non-regular enzyme preparation Wobe-Mugos. Ned Tijdschr Geneeskd 135(49): 2341-2344, 1991. PMID: 1809893.

27 Johann K, Eschmann K and Meiser P: Keine klinische Evidenz für ein erhöhtes Blutungsrisiko durch Bromelain bei perioperativem Einsatz. Sportverletzung Sportschaden 25(2): 108-113, 2011.

Received May 13, 2021 Revised May 29, 2021 Accepted June 2, 2021 